\title{
QUANTITATIVE ASPECTS OF IODINE METABOLISM. THE EX- CHANGEABLE ORGANIC IODINE POOL, AND THE RATES OF THYROIDAL SECRETION, PERIPHERAL DEGRADATION AND FECAL EXCRETION OF ENDOGENOUSLY SYN- THESIZED ORGANICALLY BOUND IODINE
}

\author{
By SOLOMON A. BERSON AND ROSALYN S. YALOW
}

(From the Radioisotope Unit, Veterans Administration Hospital, Bronx, N. Y.)

(Submitted for publication June 2, 1954 ; accepted July 7, 1954)

Of the three important quantitative aspects of iodine metabolism-thyroidal iodide accumulation, release of organically bound iodine from the thyroid and metabolism of organic iodine in the body tissues, only the first has been measured adequately in man (1). The purpose of the present report is to outline methods for the quantitative evaluation of : 1) The organic iodine pools of the body; 2) the rate of thyroidal secretion of organically bound iodine; 3 ) the metabolic degradation and fecal excretion of organically bound iodine ; ${ }^{1}$ and 4) exogenous and endogenous iodine balance.

The technical methods employed and the schematic model on which the analyses are based are common to all the determinations and are presented first. The specific analyses and results obtained for the various phases of iodine metabolism are then considered in separate sections. An attempt has been made to follow a similar order of presentation in each of these sections. The theoretical basis for the methods employed in the measurement of each aspect of iodine metabolism is followed by a sample calculation from the observed data in one of the subjects, R. D. Reference is then usually made to the results of the measurements, and the section is concluded with an analysis of the validity of the determinations and the sources of error.

\section{TECHNICAL METHODS}

Subjects were hospitalized euthyroid and hyperthyroid patients. In all cases the diagnoses were confirmed by several observers and considered established without refer-

1 This process has occasionally been referred to as hormonal iodine utilization. Since it is questionable whether the organic iodine released by the thyroid represents homogeneous hormonally active substance or whether all organic iodine which undergoes degradation is utilized in any strict metabolic sense, it seems preferable to use the more general term, organic iodine degradation, in place of hormonal iodine utilization. ence to the results obtained in the radioactive iodine tests. One hundred to two hundred $\mu \mathrm{c}$ of $\mathrm{I}^{181}$ were administered intravenously, as carrier-free sodium iodide. At intervals thereafter, radioactivity in the thyroid, blood and urinary and fecal excretions was assayed. A bismuth-walled Geiger tube was used for the thyroid assays according to methods previously described (2) and a well-type scintillation counter was employed for assays of radioactivity in blood and excreta. Five ml. samples of plasma or packed erythrocytes were counted with a sensitivity of $1.03 \times 10^{6}$ counts per minute per $\mu \mathrm{C} \mathrm{I}^{181}$ above a background of about 200 counts per minute. Two hundred $\mathrm{ml}$. samples of urine were counted in a constant geometrical relationship to the scintillation crystal with a sensitivity of $8.3 \times 10^{4}$ counts per minute per $\mu \mathrm{C} \mathrm{I}^{131}$ above a background of about 300 counts per minute. Twenty-four hour stool collections were made up to $300 \mathrm{ml}$. volumes with water, homogenized in an Oster mixer, and counted in a similar manner with a sensitivity of $3.7 \times 10^{4}$ counts per minute per $\mu \mathrm{C} \mathrm{I}^{131}$. $\mathrm{PBI}^{127}$ in plasma was determined by the method of Barker, Humphrey, and Soley (3).2

$\mathrm{PBI}^{131}$ and iodide ${ }^{131}$ in plasma were determined from assays of plasma and packed red cells utilizing the plasma: erythrocyte ratio of iodide' 131 (usually 1.6 to 1.8 ) for each subject and the observation that $\mathrm{PBI}{ }^{121}$ is not detectable in packed cells when allowance is made for trapped plasma. In many instances 10 per cent cold trichloracetic acid was added to the plasma and precipitate and filtrate were separately assayed. However, since it was observed that trichloracetic acid frequently precipitated significant quantities of I $^{131}$ as iodide added to plasma, the method described above was considered more reliable for the quantitative separation of iodide and PBI. Complete urine and stool collections were made during the periods of observation in most of the cases. After there appeared to be equilibration of the $I^{131}$ in the exchangeable organic iodine pool, 1-methyl-2 mercaptoimidazole (tapazole) was administered in doses of 25 to $30 \mathrm{mgm}$. every six hours, which are sufficient to inhibit thyroidal iodide binding almost completely (4).

In another type of experiment, the concentration of $\mathrm{PBI}^{131}$ in the plasma was followed for about 10 days in three subjects who received labeled plasma from a donor treated with 8.5 mc. I ${ }^{131}$ for Graves' disease.

$2 \mathrm{We}$ are indebted to Dr. Solomon Silver and to Mr. Herbert Lew in the laboratory of Dr. Bruno Volk for these determinations. 
SCHEMATIC MODEL

For the purpose of orientation, the major pathways of iodine transport are summarized briefly with reference to the schematic model shown in Figure 1. Intravenously administered radioiodide is distributed rapidly among the iodide pools of blood, tissue fluids, and thyroid gland. Clearance of the total iodide pool is effected by binding in the thyroid and excretion in the urine. Organically bound $I^{131}$ released from the thyroid into the plasma and tissue fluids is subject to metabolic degradation, the principal end product being iodide which then repeats the cycle. A small amount of non-protein bound organic iodine is also excreted by the kidneys (5) but usually comprises only a small fraction of the total urinary iodine. There is also a loss of organic iodine in the stool which may represent only a fraction of the total iodine transfer through the

\section{MAJOR PATHWAYS IN TRANSPORT OF IODINE}

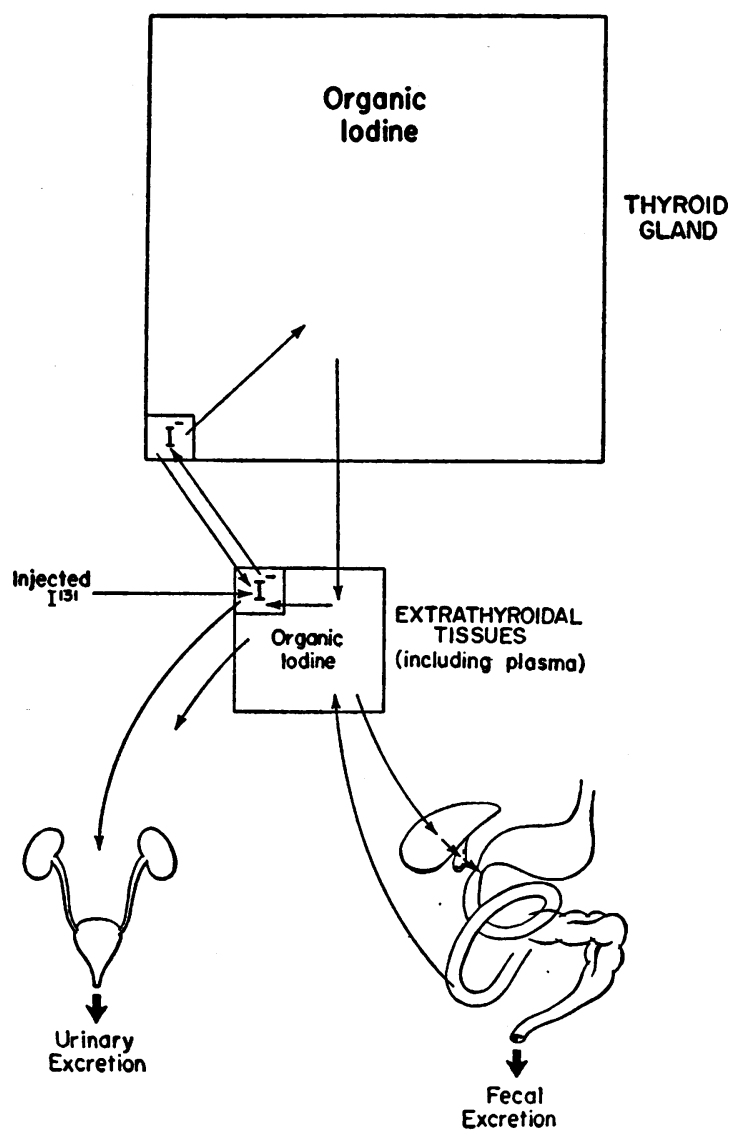

Figure 1

See text for discussion.

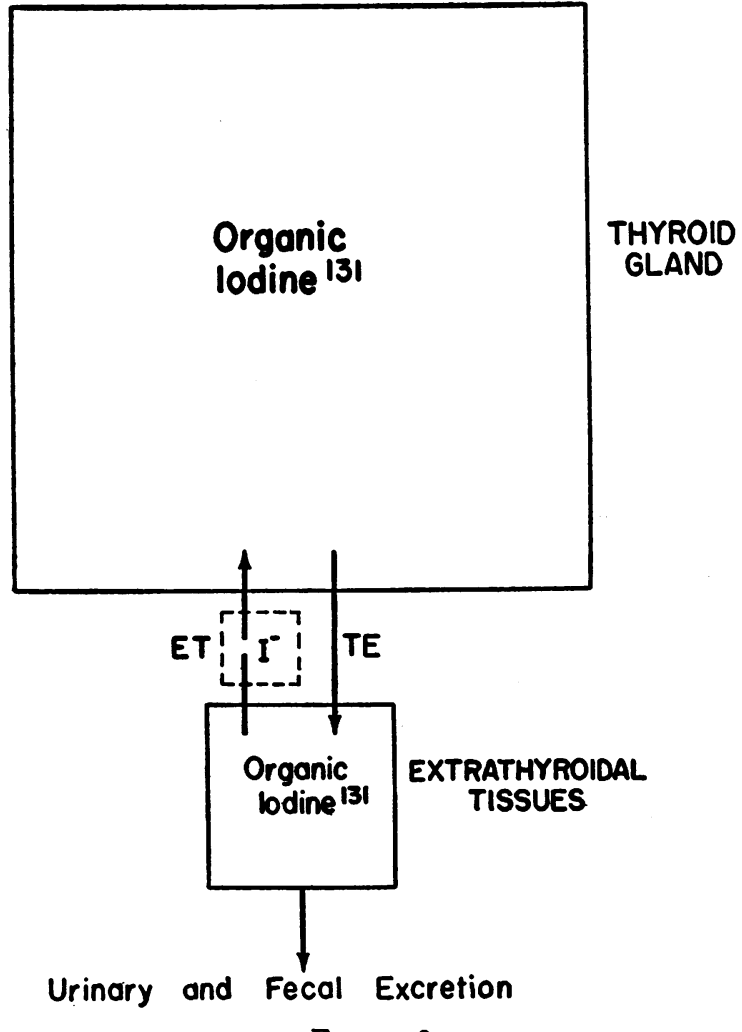

FIGURE 2

Following peak thyroidal uptake and renal excretion of the administered iodide ${ }^{131}$, the radioactive iodine remaining in the body is almost entirely in an organic form undergoing distribution between thyroidal and extrathyroidal organic iodine pools. See text for discussion.

enterohepatic circulation (6). Since virtually the entire administered dose of $I^{131}$ was accounted for in the urinary and stool excretions in our cases followed for prolonged periods, no other major excretory pathway need be considered. The radioiodine retained in the body at any time $\left(\mathrm{I}_{\mathrm{ret}}^{131}\right)$ is then determined by subtracting the cumulative urinary and fecal excretions from the dose administered.

In normal and hyperthyroid subjects, the total iodine present in the enterohepatic circulation and in the iodide fraction of the thyroid and extrathyroidal tissues at any time represents only a small part of the total iodine content of the body. Therefore, following initial clearance of the administered radioiodide, the major portion of the radioiodine in the body may be considered to be undergoing distribution between two compartments, the thyroidal and extrathyroidal organic iodine pools (Figure 2), which are in 
dynamic equilibrium. A transient iodide phase is interposed in the pathway from extrathyroidal to thyroidal compartments.

\section{PART I-ESTIMATION OF THE ORGANIC IODINE POOLS OF THE BODY}

These determinations are based on the assumption that when a tracer substance has mixed uniformly in all its compartments of distribution, the specific activity is the same in all these compartments and, in the absence of turnover, remains constant. In the present section radioactivity is treated only in terms of the $I^{131}$ remaining in the body ( $\left.\mathrm{I}_{\text {rot }}^{131}\right)$ thus obviating the necessity for consideration of turnover of the pool with newly ingested iodine.

\section{A. The total exchangeable organic iodine pool}

Following peak uptake by the thyroid, the curves of thyroidal radioactivity and plasma concentration of $\mathrm{PBI}{ }^{131}$, plotted as fractions of $\mathrm{I}_{\mathrm{ret}}^{131}$ vs. time, each approach an horizontal asymptote

(Figures 3a, 4). The maintenance of horizontal plateaus in these curves over a period of several weeks indicates that the radioiodine tracer has mixed uniformly in an organic iodine pool which remains constant at least over this period of time, and which, therefore, has been called "the exchangeable organic iodine pool." This pool is calculated from the ratio $\frac{\mathrm{PBI}^{127} / \text { liter plasma }}{\text { fraction } \mathrm{I}_{\text {ret }}^{131} / \text { liter plasma }}$ at distribution equilibrium.

Calculation-In R. D. (Figure 3a), distribution equilibrium was attained by the 7 th day, at which time the fraction $I_{\text {ret }}^{131}$ per liter of plasma was .015 . Since PBI ${ }^{127}$ was 154 micrograms per liter, the total exchangeable organic iodine pool $=\frac{154 \mathrm{micrograms} / \text { liter }}{.015 / \text { liter }}$ $=10,300$ micrograms.

In most untreated hyperthyroid and euthyroid subjects the total exchangeable organic iodine pool ranged from about 7000 micrograms to 13,000 micrograms with a few almost as high

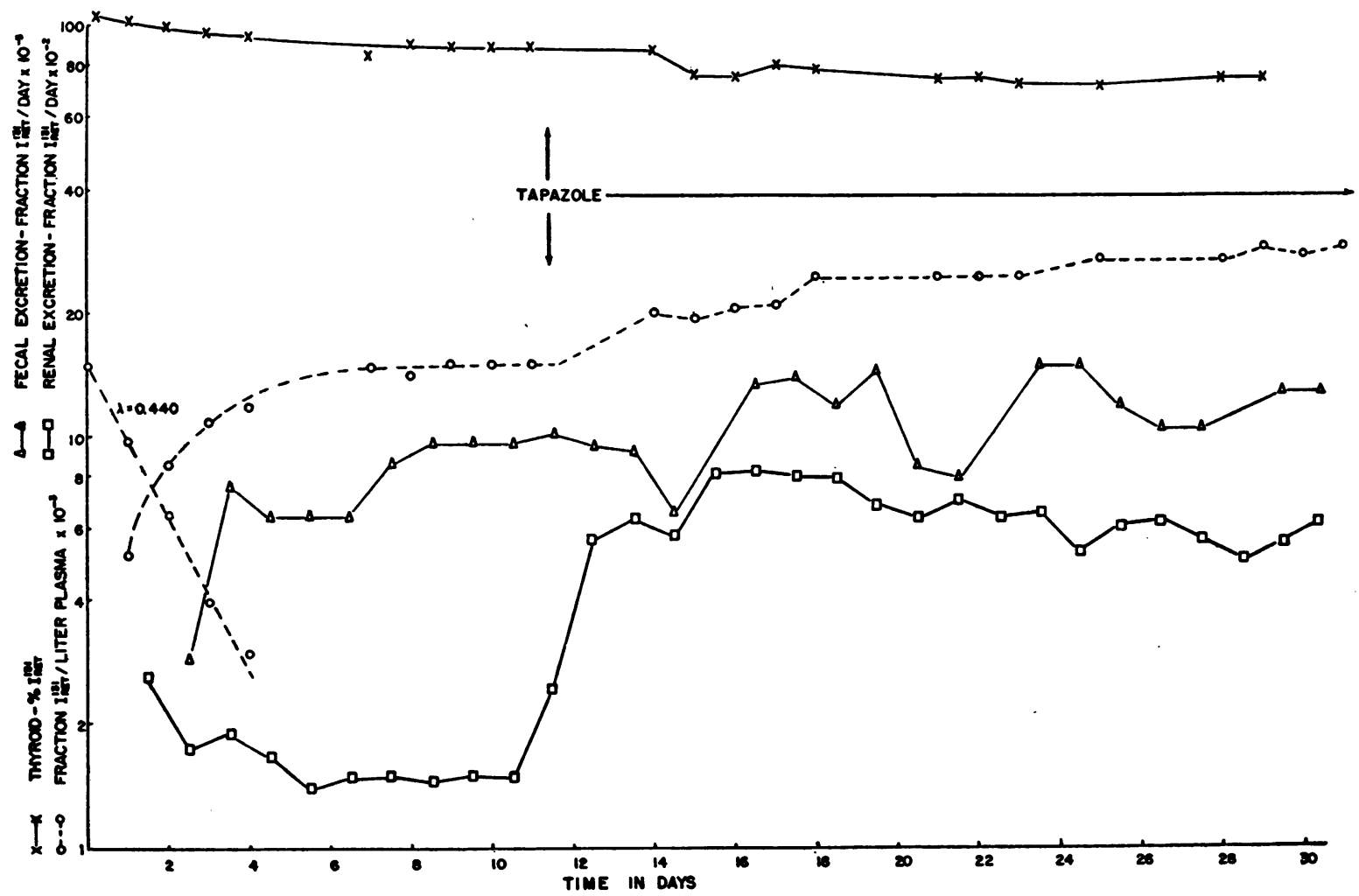

Fig. 3a. Radioactivity (Fraction I I 131 ) in Thyroid and Plasma aNd in Urinary and Fecal Excretions in SUbJect R. D.

The urine excretions are plotted at mid-day. 


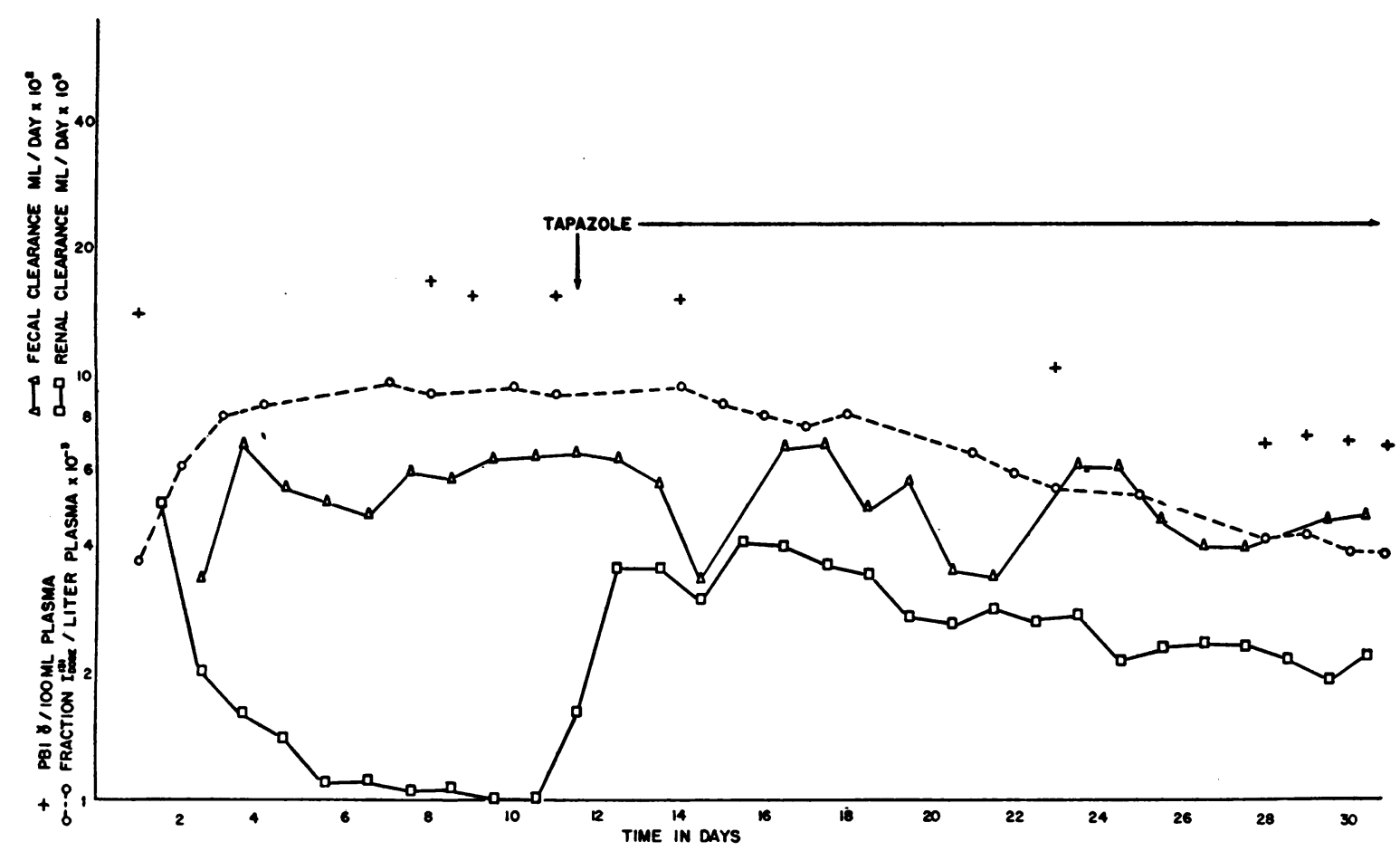

Fig. 3b. Plasma Concentrations of PBI'19 and PBI ${ }^{127}$ and Apparent Fecal and Renal Plasma Organic Iodine Clearances in Patient R. D.

The latter were determined by dividing the daily excretions by the plasma concentrations. Plasma PBI ${ }^{111}$ concentrations are plotted as fractions of the administered dose of $I^{131}$ per liter.

as 20,000 micrograms (Table I). The pool sizes were generally much reduced in those subjects who had been treated previously with tapazole, radioiodine or surgery.

Inactive pools not entered by the administered radioiodine cannot, of course, be detected under these circumstances. However, the maintenance of a constant specific activity in the plasma for several weeks (Figure 5), during anti-thyroid therapy with tapazole, when thyroidal and plasma radioactivity may fall to $\mathbf{5 0}$ per cent or less of the control values, indicates that such unexchangeable pools which might exist are not readily mobilized, even in the presence of moderate depletion of iodine stores.

In one euthyroid subject (G. M., Figure 4), a plateau in the plasma concentration $\left(\mathrm{I}_{\text {ret }}^{131}\right)$ curve was not obtained even after several weeks. The size of his exchangeable organic iodine pool as given in Table $\mathrm{I}$ is therefore overestimated since it was calculated from the specific activity on the last day of observations, instead of the higher specific activity which would have been obtained at equilibrium.

\section{B. Thyroidal and extrathyroidal fractions of ex- changeable organic iodine pool}

At the time of peak uptake of the administered radioiodide by the thyroid only negligible amounts of organically bound iodine have been released from the thyroid. The fall in thyroidal radioactivity (fraction $\mathrm{I}_{\mathrm{ret}}^{131}$ ) from peak uptake to the asymptotic value then represents the portion of organic iodine in extrathyroidal tissues and the asymptotic value itself is the portion remaining in the thyroid at distribution equilibrium.

Calculation-In R. D. (Figure 3a) thyroidal radioactivity fell from a peak uptake value of 108 per cent to an asymptote of 89 per cent. The extrathyroidal fraction of the total exchangeable organic iodine pool is, therefore, $\frac{108-89}{108}=18$ per cent and the thyroidal fraction $=82$ per cent. Utilizing the value for the total pool as given above $(10,300$ micrograms), the thyroidal and extrathyroidal pools are calculated to contain 8,450 micrograms and 1,850 micrograms respectively. 
In euthyroid subjects not previously treated for hyperthyroidism (G. M. and R. F., Table I) the thyroid contained about 95 per cent and the extrathyroidal tissues about 5 per cent of the total exchangeable organic iodine pool. In untreated hyperthyroid subjects the extrathyroidal fraction generally ranged from 10 to 20 per cent of the total but in hyperthyroid and euthyroid subjects with reduced total pools (usually a result of previous therapy), the extrathyroidal compartment frequently contained 30 per cent or more of the total organic iodine (Table I).

The quantity of organic iodine in the extrathyroidal tissues was, of course, greater in hyper-

I. TIME OF PEAK - AYROIDAL UPTAKE
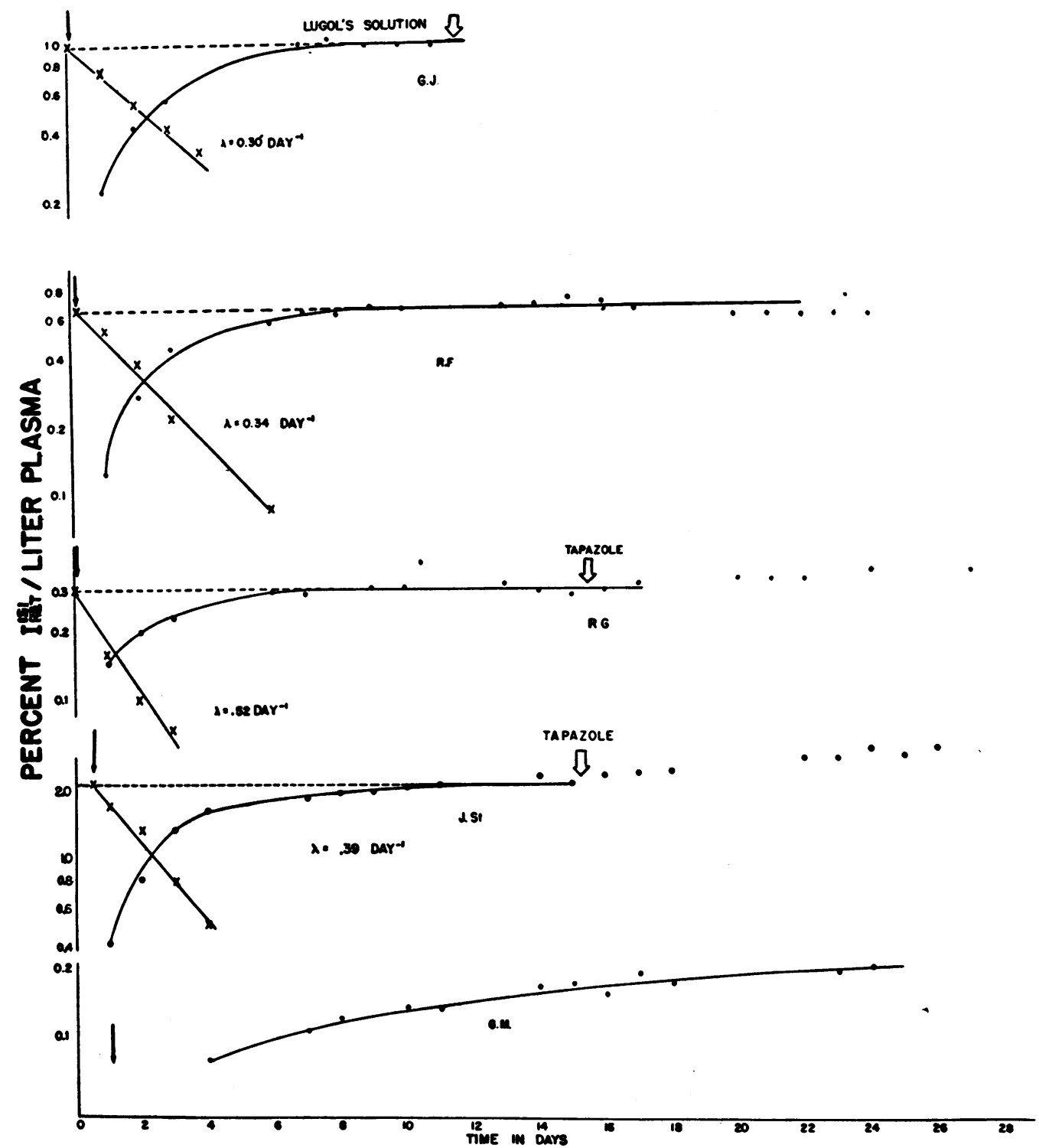

Fig. 4. Plasma Concentrations of PBIm in Terus of Iret as a Function of Time

The rate of equilibration is found from the slope of the line joining the points of differences between the curve and the asymptotic value. $\lambda$ as given in the figure is equal to $\lambda_{\mathrm{ET}}+\lambda_{\mathrm{TE}}$ of the text. In G. M., equilibrium was not reached at the end of 24 days. In the remaining cases about one week was required for equilibration. See also $R$. D. in Figure 3a. 


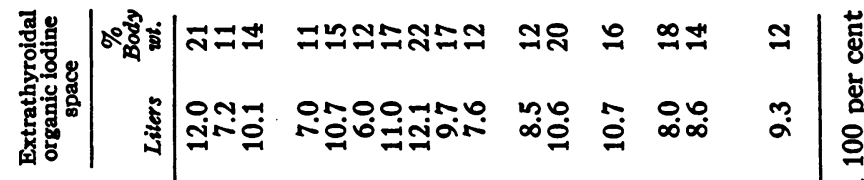

ষ

党

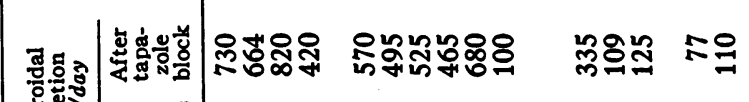

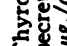

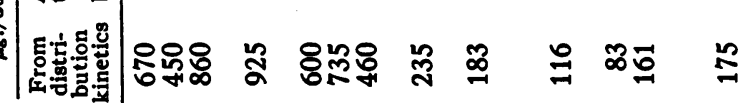

ฮై

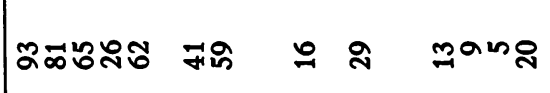

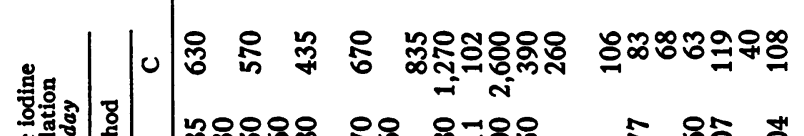

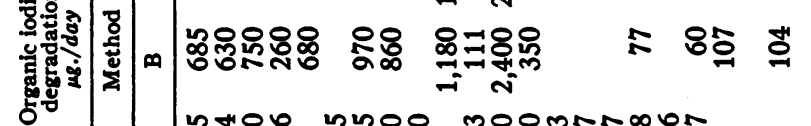

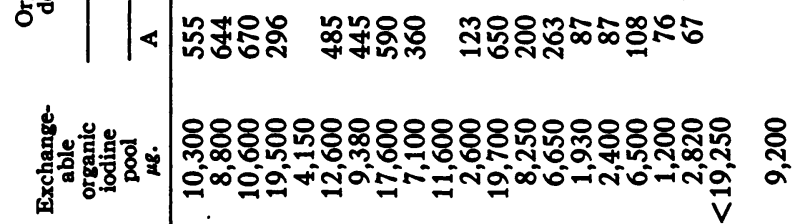

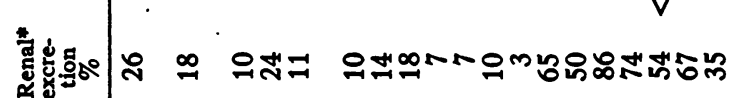

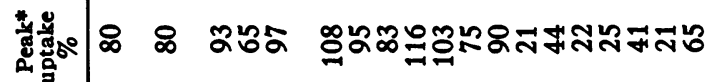

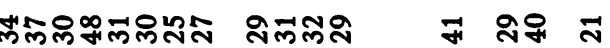

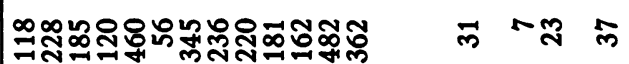

疍
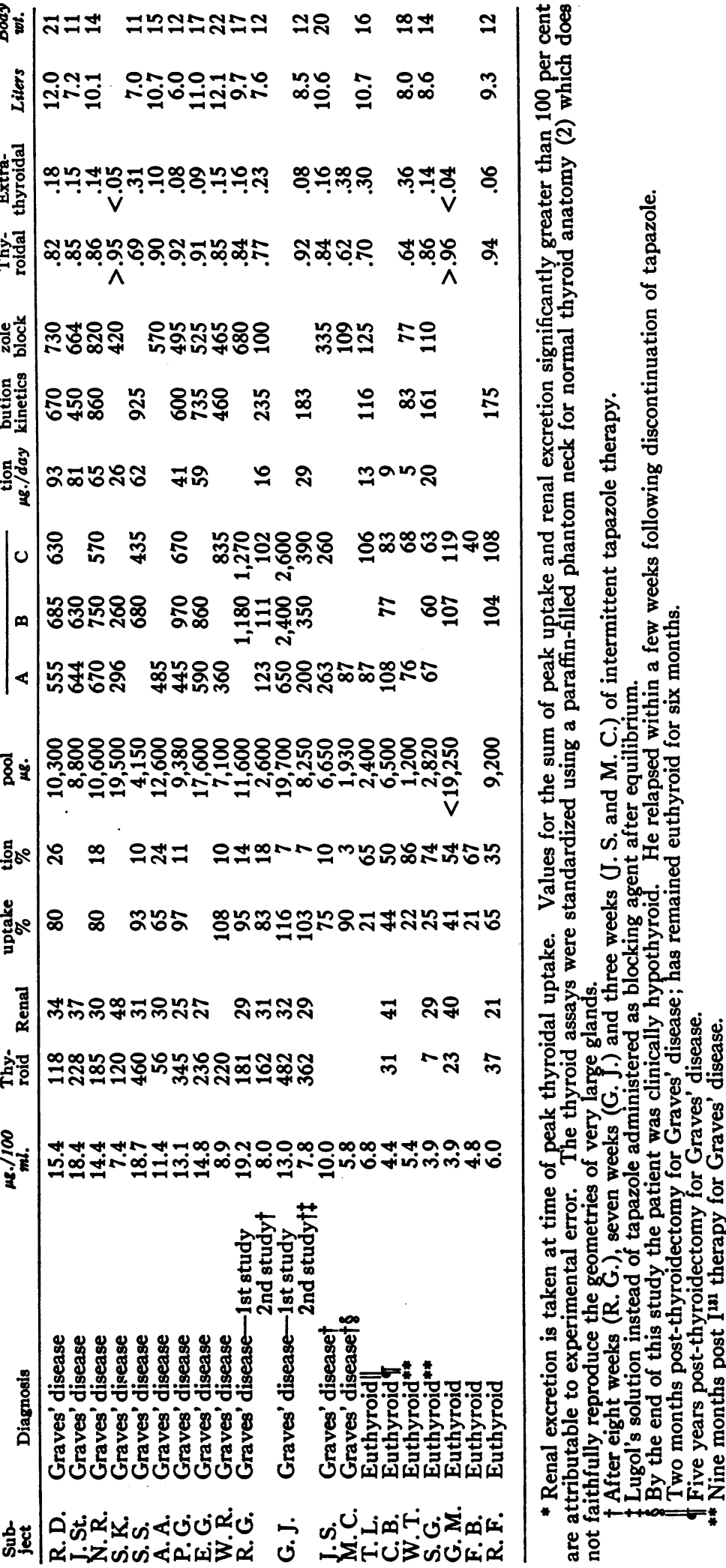

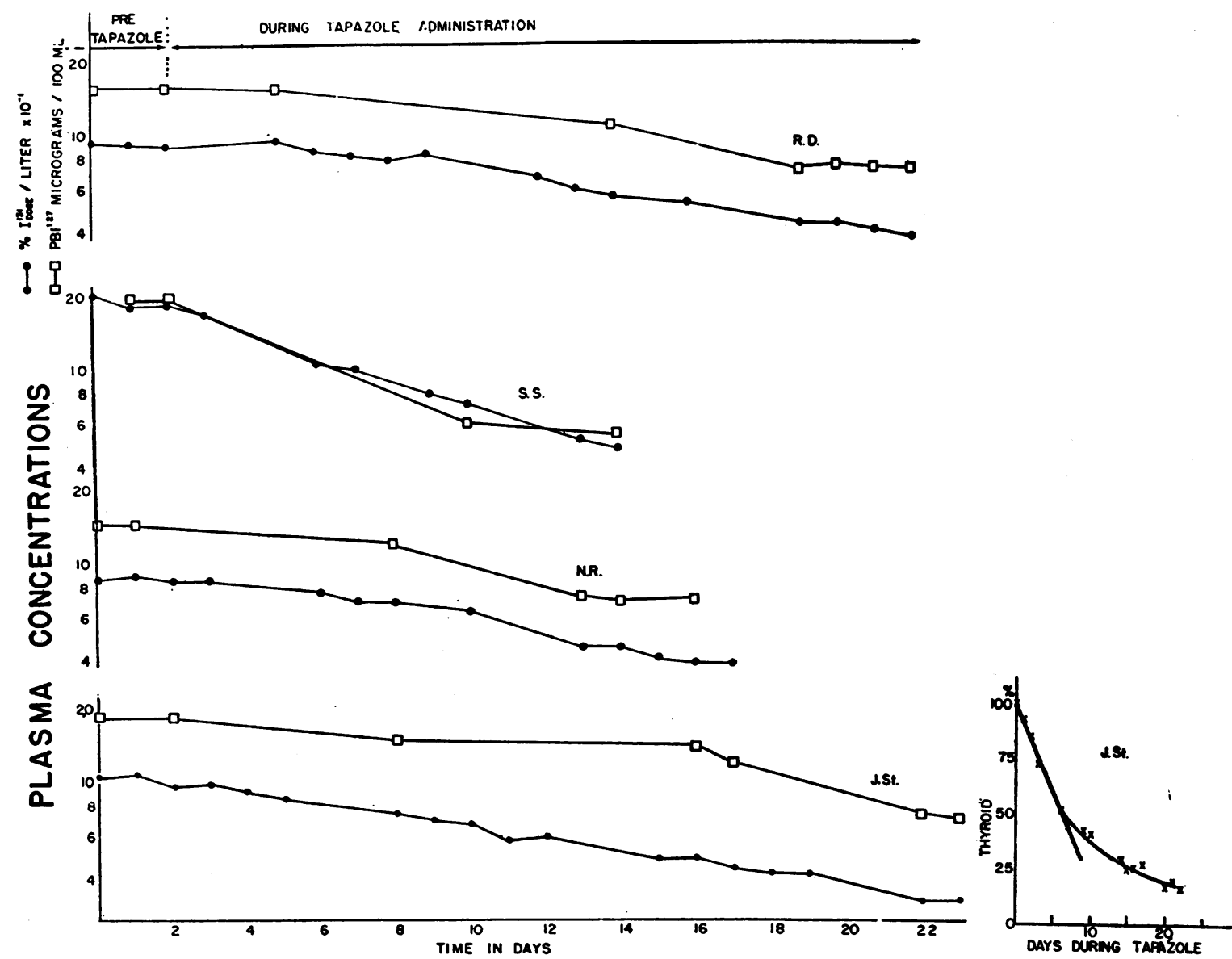

Fig. 5. Plasma Concentrations of PBI ${ }^{127}$ and PBiri (Plotted as Per Cent of the Admanstered Dose PER Liter) Following Administration of Tapazole

Also shown is the thyroidal radioactivity of J. St. relative to the first day of tapazole administration. The ratio between $\mathrm{PBI}^{197}$ and $\mathrm{PBI}{ }^{12}$ is not significantly different after 22 days of tapazole inhibition and the loss of over 80 per cent of thyroidal $I^{121}$.

thyroid than in euthyroid subjects and averaged about 570 micrograms (range, 400 to 750 micrograms) in the latter group.

The thyroidal pool alone may be evaluated after distribution equilibrium has been attained without knowledge of the I ${ }^{131}$ retained, since thyroidal and plasma specific activities are then essentially the same $^{\mathbf{s}}$ and thyroidal and plasma radioactivity and plasma $\mathrm{PBI}^{127}$ are measurable.

\footnotetext{
3 Theoretically the specific activities are never identical except at a single point (7), since excretion occurs solely from the extrathyroidal pool. However, since the rate of excretion of the total exchangeable pool is only about $1 \frac{1}{2}$ per cent per day as compared to half times of 1 to 3 days for equilibrium between thyroidal and extrathyroidal pools, the specific activities are virtually identical after the plasma peak is reached.
}

This determination suffers from uncertanty as to the time of distribution equilibrium, in the absence of data on $I^{131}$ retained. However, equilibrium of distribution may be presumed when thyroidal and plasma curves show a parallel decline.

\section{The extrathyroidal space of distribution of or- ganic iodine}

1. Estimations utilizing endogenously synthesized organic iodine

Of the $\mathrm{PBI}{ }^{131}$ which is retained in the body, that which is not in the thyroid is distributed in the extrathyroidal tissues. Therefore, the apparent volume of distribution may be calculated from the expression $\frac{\text { fraction } I_{\mathrm{rot}}^{131} \text { in extrathyroidal pool }}{\text { fraction } I_{\mathrm{rot}}^{181} \text { per liter plasma }}$ 
at any time. The experimental error is smallest when the estimation is made after distribution equilibrium is attained.

Calculation-Substituting the values calculated above in R. D., the extrathyroidal space = $\frac{0.18}{.015 / \text { liter plasma }}=12$ liters.

The extrathyroidal space of distribution of endogenously synthesized organic iodine ranged between 6 and 12 liters (11 to 22 per cent of body weight) with no evident significant differences between euthyroid and hyperthyroid subjects (Table I). The individual figures may be subject to errors as great as 30 per cent, being derived from relatively small differences in thyroidal radioactivity.

\section{Estimations utilizing exogenously biosyn- thesized organic iodine}

In order to evaluate more precisely the space of distribution of organic iodine, plasma from a patient with Graves' disease was obtained three days after a therapeutic dose of $8.5 \mathrm{mc}$. of $\mathrm{I}^{\mathbf{1 3 1}}$ and was administered intravenously to three recipients, one with hyperthyroidism, one with euthyroidism, and one with hypothyroidism. Table II summarizes the data with respect to this experiment and Figure 6 shows the plasma concentration curves for about 10 days following the injections. The terminal exponential decreases in concentration are presumably due to degradation and excretion of undegraded hormone, while the earlier portions of the curves represent the simultaneous processes of degradation and mixing in the extrathyroidal compartment. Although there is a continued increase in the space of distribution over a period of about 48 hours, the major fraction is distributed within 4 to 6 hours. In each case, the approximate volume of distribution of exogenous organic iodine was calculated from the total administered radioactivity divided by the $\mathrm{PBI}{ }^{131}$ concentration at the zero time extrapolation of the terminal straight line portion of the curve (Figure 6).

The volumes in the three cases ranged from 8.7 to 11.7 liters (10.3 to 20.6 per cent body weight) which agree reasonably with the values obtained for endogenous organic iodine.

\section{PART II-THYROIDAL SECRETION OF ORGANIC IODINE}

\section{A. Estimation of secretion rate from the kinetics of distribution of organic iodine between thy- roidal and extrathyroidal pools}

Assuming that steady state conditions obtain during the course of the experiment, analysis of

TABLE II

Data pertaining to distribution and degradation of exogenously synthesized organic iodine * $f$

\begin{tabular}{|c|c|c|c|c|c|c|c|c|c|}
\hline \multirow[b]{2}{*}{ Subject } & \multirow[b]{2}{*}{ Diagnosis } & \multirow[b]{2}{*}{$\begin{array}{c}\text { Counts/min. } \\
\text { transfused }\end{array}$} & \multirow[b]{2}{*}{$\begin{array}{c}\text { Date } \\
\text { admin. }\end{array}$} & \multirow[b]{2}{*}{$\begin{array}{l}\text { PBI } \\
\text { M8./100 ml. }\end{array}$} & \multicolumn{2}{|c|}{$\begin{array}{c}\text { Space of } \\
\text { distribution }\end{array}$} & \multirow{2}{*}{$\begin{array}{c}\text { Extrathyroidal } \\
\text { pool一organic } \\
\text { iodine } \\
\mu g .\end{array}$} & \multirow{2}{*}{$\begin{array}{c}\text { Turn- } \\
\text { over } \\
\text { rate } \\
\% / d a y\end{array}$} & \multirow{2}{*}{$\begin{array}{c}\text { Rate of } \\
\text { degrada- } \\
\text { tiont } \\
\text { ug./day }\end{array}$} \\
\hline & & & & & Liters & $\begin{array}{c}\text { \% Body } \\
\text { wot. }\end{array}$ & & & \\
\hline R.A. & $\begin{array}{l}\text { Hypothyroid } \\
\text { (post thyroid- } \\
\text { ectomy for }\end{array}$ & $3.42 \times 10^{6}$ & $5 / 25 / 53$ & 1.7 & 8.7 & 10.3 & 148 & 9.76 & 13 \\
\hline $\begin{array}{l}\text { F. S. } \\
\text { G. Mi. }\end{array}$ & $\begin{array}{l}\text { Euthyroid } \\
\text { Hyperthyroid } \\
\text { (intermittent } \\
\text { therapy with } \\
\text { tapazole for } \\
\text { several weeks } \\
\text { prior to study) }\end{array}$ & $\begin{array}{l}2.78 \times 10^{6} \\
5.93 \times 10^{6}\end{array}$ & $\begin{array}{l}5 / 25 / 53 \\
5 / 26 / 53\end{array}$ & $\begin{array}{r}6.7 \\
11.2\end{array}$ & $\begin{array}{r}9.1 \\
11.7\end{array}$ & $\begin{array}{l}12.1 \\
20.6\end{array}$ & $\begin{array}{r}610 \\
1,310\end{array}$ & $\begin{array}{l}12.4 \\
22.0\end{array}$ & $\begin{array}{r}68 \\
256\end{array}$ \\
\hline
\end{tabular}

* Donor, M. C. (Graves' disease) was given $8.45 \mathrm{mc}$. I ${ }^{1 \mathrm{n}}$ on 5/22/53. On 5/25, 98.5 per cent of radioactivity in plasma was precipitated by 10 per cent cold trichloracetic acid; 72.6 per cent was butanol soluble; 26.6 per cent was present in the butanol insoluble fraction. $\mathrm{Na}_{2} \mathrm{CO}_{2}$ and $\mathrm{NaOH}$ extract of the butanol soluble fraction contained 2 per cent of the total radioactivity.

t Recipients were maintained on $25 \mathrm{mg}$. tapazole every six hours to prevent reaccumulation of degraded iodine by the thyroid. 92 to 102 per cent of the radioactivity in the plasma samples of the recipients was precipitable with 10 per cent cold trichloracetic acid.

$\ddagger$ Turnover was assumed to be due to degradation plus fecal excretion. The rates of degradation were calculated by estimating fecal excretion of undegraded hormone at $12 \frac{1}{2}$ per cent of the rate of degradation. 


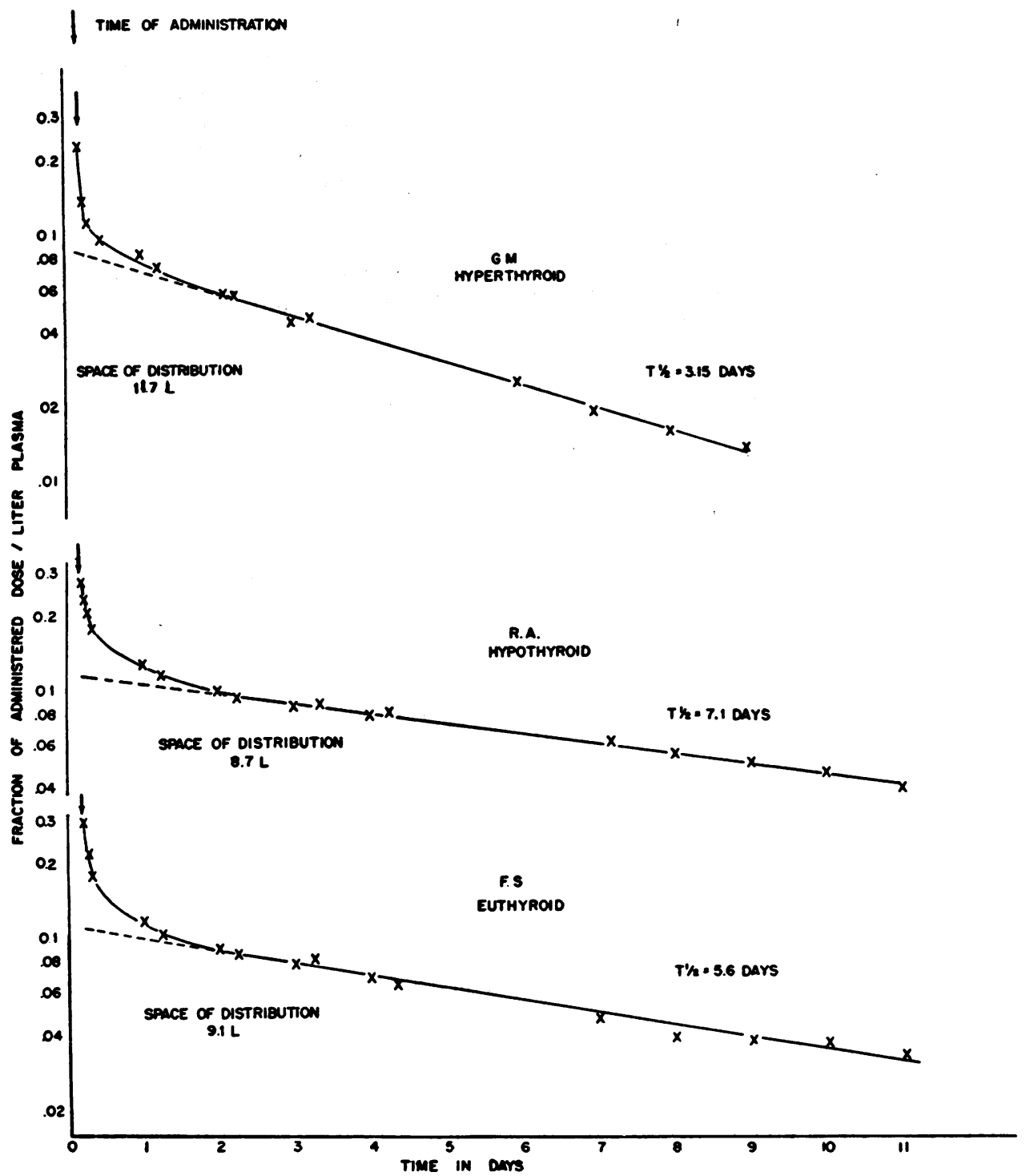

Fig. 6. Plasma Concentration Curves of Radioactivity as a Function of Tnge Following the Intravenous InJection of ExogenousLy Synteesized Organic Iodine (Ser.Table,II) da

The 15 minute spaces of distribution approximate the plasma volumes.

the kinetics of distribution of $\mathrm{PBI}^{131}$ between thyroidal and extrathyroidal compartments permits a reasonable estimate of the rate of organic iodine secretion from the thyroid to be made in many cases (Table I).

Let $T$ and $E$ be the radioactivity in terms of fraction $\mathrm{I}_{\text {rot }}^{131}$ in the thyroidal and extrathyroidal organic iodine pools respectively at any time, $t$, following peak uptake. Let $\lambda_{\mathrm{TF}}$ and $\lambda_{\mathrm{ET}}$ be the rate constants of transfer between thyroidal and extrathyroidal pools in the order of the subscript designations. Then,

$$
\begin{aligned}
& \frac{d T}{d t}=-\lambda_{T E} T+\lambda_{E T} E \\
& \frac{d E}{d t}=-\lambda_{E T} E+\lambda_{T E} T
\end{aligned}
$$

On substituting,

$$
\text { at } \mathrm{t}=0 \quad \mathrm{~T}=\mathrm{T}_{0}=1, \mathrm{E}=0
$$

and

$$
\text { at } \mathrm{t}=\infty \quad \mathrm{T}=\mathrm{T}_{\infty}, \quad \mathrm{E}=\mathrm{E}_{\infty}=\mathrm{T}_{0}-\mathrm{T}_{\infty}
$$


the solution of these equations yields the following expressions for the radioactivity in thyroidal and extrathyroidal pools.

$$
\begin{aligned}
& \mathrm{T}=\mathrm{T}_{\infty}+\left(1-\mathrm{T}_{\infty}\right) \mathrm{e}^{-\left(\lambda_{\mathrm{TE}}+\lambda_{\mathrm{ET}}\right) \mathrm{t}} \\
& \mathrm{E}=\mathrm{E}_{\infty}\left(1-\mathrm{e}^{-\left(\lambda_{\mathrm{TE}}+\lambda_{\mathrm{ET}}\right) \mathrm{t}}\right)
\end{aligned}
$$

where $\left(\lambda_{\mathrm{TE}}+\lambda_{\mathrm{ET}}\right)$ equals the rate of approach of the curves to the asymptotic values. This rate is obtained from the plasma concentration curves (Figures $3 \mathrm{a}$ and 4 ) since these values have much greater reliability than those for the thyroidal radioactivity. Since $\lambda_{\mathrm{ET}} \mathrm{E}_{\infty}=\lambda_{\mathrm{TE}} \mathrm{T}_{\infty}, \lambda_{\mathrm{TE}}$ can be readily evaluated. The rate of thyroidal secretion is then given by the product of $\lambda_{\mathrm{TE}}$ and the thyroidal organic iodine pool.

Calculation-In R. D. (Figure 3a), $\lambda_{\mathrm{ET}}+\lambda_{\mathrm{TE}}$ $=0.440$ days $^{-1} . \quad E_{\infty}$ and $T_{\infty}$ as calculated above are 0.18 and 0.82 , respectively. Then, $0.18 \lambda_{\mathrm{ET}}=0.82 \lambda_{\mathrm{TE}}$. Solving from both equations $\lambda_{E T}=.079$ days $^{-1}$. Since the thyroidal organic iodine pool as calculated above is 8,450 micrograms, the rate of thyroidal secretion $=.079$ per day $\times 8,450$ micrograms $=670$ micrograms per day.

When the fall in thyroidal radioactivity (fraction $I_{\text {ret }}^{131}$ ) from $T_{0}$ to $T_{\infty}$ is less than 5 per cent or so, the calculated value for $\mathrm{E}_{\infty}$ is too unreliable to justify estimates of $\lambda_{\text {TE. }}$.

If distribution of organic iodine between thyroid and extrathyroidal tissues were significantly complicated by the time lag in mixing among the multiple spaces of the extrathyroidal compartment or by the possible failure of the radioiodine to mix uniformly in the functional thyroid pool, the analysis would require more than a single exponential component to describe the approach of the curves to the asymptotic values (8). However, in all the cases of this study, distribution appeared to take place at a single rate (Figures $3 a, 4)$ and it may be recalled that mixing within the extrathyroidal pool (Figure 6) is quite rapid compared to distribution between thyroidal and extrathyroidal pools (Figure 4).

\section{B. Estimation of secretion rate from the decrease in thyroidal radioactivity during tapazole inhibition}

If the thyroid is prevented from reaccumulating radioiodide released by degradation of extrathyroidal organically bound iodine, the ob- served rate of decrease in thyroidal radioactivity should be a measure of thyroidal secretion. Therefore, during the administration of tapazole, thyroidal secretion of organic iodine was calculated as the product of the percentage rate of fall in thyroidal radioactivity and the thyroidal organic iodine pool.

Calculation-In R. D. (Figure 7) the thyroid lost 8.5 per cent per day of its initial activity for the first five days of tapazole therapy. Since the thyroid contained 8,450 micrograms of organic iodine at the onset of treatment, as calculated above, the rate of thyroidal secretion $=8.5$ per cent per day $X$ 8,450 micrograms $=720$ micrograms per day.

Thyroidal secretion remained fairly constant for the first five to seven days of tapazole therapy but usually decreased thereafter in subjects with high rates of secretion (Figure 7, and J.St. in Figure 5). Values derived from the initial rates of secretion showed a range of 77 to 125 micrograms per day in euthyroid subjects and 450 to 925 micrograms per day in untreated hyperthyroid subjects (Table I).

The validity of these determinations is based on the assumption that the drug acts only to block thyroidal binding of iodine and has no direct effect on the rate of thyroidal secretion. The reasonable agreement between the values for thyroidal secretion obtained by this method and those calculated from the kinetics of distribution suggests that tapazole neither increases nor decreases the rate of secretion, at least initially. Further speculations regarding possible effects of tapazole on thyroid secretion are deferred to the Discussion.

An additional concern was whether an increase in the thyroidal iodide pool during tapazole administration was likely to introduce any error into the measurements of thyroidal organic $I^{131}$ and, therefore, into the calculations for thyroidal secretion. However, quantitative considerations indicate that in the absence of marked impairment of renal iodide excretion one may continue to regard all thyroidal radioactivity as organically bound without appreciable error. ${ }^{4}$

1 This was experimentally confirmed in two subjects (P. G. and E. G.). In both cases $1.0 \mathrm{gm}$. sodium thiocyanate given intravenously after two and three weeks, respectively, of continuous tapazole administration failed 


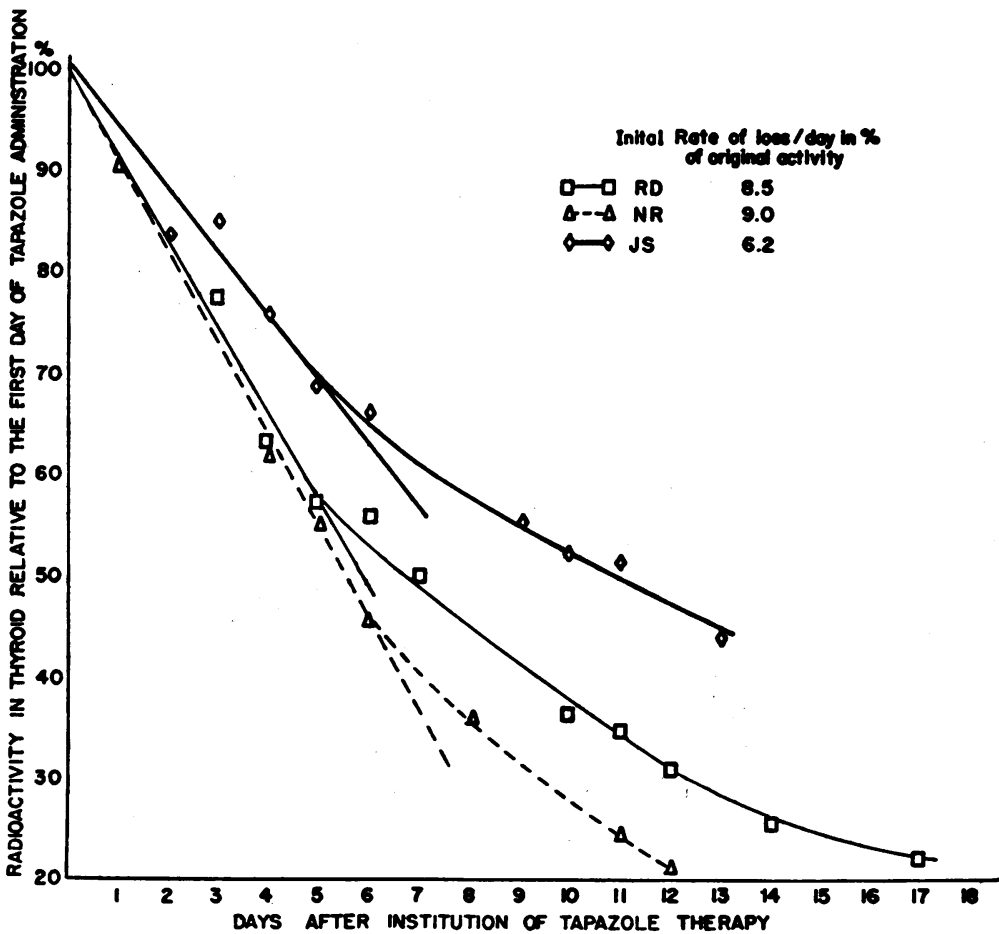

Fig. 7. Radioactivity in the Thyroid During Tapazole Administration

During the first five to seven days of therapy a constant amount of organic $\mathrm{I}^{1 \mathrm{n}}$ is secreted daily by the thyroid.

PART III-METABOLIC DEGRADATION AND FECAL EXCRETION OF ORGANIC IODINE

\section{A. Estimation of the rate of degradation from the} renal "clearance" of plasma organic iodine 1. In the presence of tapazole block

Iodide released by metabolic degradation of extrathyroidal organic iodine is either excreted in the urine or reaccumulated by the thyroid. If thyroidal binding is completely blocked by large doses of tapazole, essentially all the iodide is excreted in the urine. Thus, although the kidneys do not directly clear the plasma of organic iodine to any significant extent, urinary iodide $^{181}$ under these conditions, represents clear-

to produce any detectable decrease in the residual thyroidal radioactivity over a two-hour period following the injections, demonstrating that there was no significant thyroidal iodide $^{121}$ at this time. To prove that this dose of sodium thiocyanate was sufficient to discharge thyroidal iodide when present, tracer tests with $I^{1 n}$ were performed one week later during tapazole inhibition of binding. In these studies all thyroidal radioactivity accumulated was discharged within a half hour by the same dose of thiocyanate. ance of metabolized plasma organic iodine (after the initially administered iodide ${ }^{181}$ has disappeared from the circulation). This clearance has been termed "the apparent renal plasma organic iodine clearance" and is calculated from the daily (24-hour) urinary excretions of $I^{181}$ divided by the mean plasma concentration of $\mathrm{PBI}^{131}$ over the 24 -hour periods. The clearance rate is expressed as ml. plasma per day (Figure $3 \mathrm{~b})$, and is multiplied by the mean plasma $\mathrm{PBI}{ }^{127}$ concentration over the same period of time to give the rate of metabolic degradation of organic iodine $^{127}$ during tapazole administration.

Calculation-In R. D. (Figure 3b) the mean apparent renal plasma organic iodine clearance rate during the first few days of tapazole administration (12th to 16th days inclusive) averaged 3.60 liters per day. Since the plasma $\mathrm{PBI}^{127}$ concentration at this time was 154 micrograms per liter, the rate of organic iodine degradation $=3.60$ liters per day $\times 154$ micrograms per liter $=555 \mathrm{mi}$ crograms per day. 
The values for the rate of organic iodine degradation calculated by this method are given under the column headed Method A in Table I. In euthyroid subjects the rates ranged from $67 \mathrm{mi}-$ crograms to 108 micrograms per day.

In addition to the determinations made immediately after the institution of tapazole therapy, such measurements were also obtained at intervals during the course of therapy, as the plasma PBI concentrations decreased, in a number of the hyperthyroid subjects.

Calculation-In R. D. (Figure $3 \mathrm{~b}$ ) the mean apparent renal plasma organic iodine clearance rate after about two and one-half weeks of tapazole therapy (28th to 31st days inclusive) was 2.1 liters per day. Since the plasma $\mathrm{PBI}^{127}$ concentration was 69 micrograms per liter at this time, the rate of organic iodine degradation was 2.1 liters per day $\times 69$ micrograms per liter $=144$ micrograms per day.

Degradation rates obtained by this method during the course of tapazole induced remissions are plotted together with the initial determinations as a function of the $\mathrm{PBI}^{127}$ concentrations in Figure 8. The degradation rates in hyperthyroid patients brought to normal PBI levels did not differ significantly from the values obtained in euthyroid subjects. In all hyperthyroid patients followed in this manner the "clearance" rates decreased strikingly as the plasma $\mathrm{PBI}^{127}$ concentrations fell (Figure $3 \mathrm{~b}$ ).

\section{In the absence of tapazole block}

If reuptake of iodide ${ }^{131}$ released by degradation of organic iodine ${ }^{131}$ is not inhibited by tapazole or other agents, the radioiodide reaccumulated by the thyroid may be calculated from the urinary excretions of radioiodine and the $\frac{\text { thyroidal }}{\text { renal }}$ iodide accumulation ratio, assuming that all urinary $\mathrm{I}^{131}$ is in the form of iodide. Neglecting objections to this assumption for the moment, the rate of metabolic degradation of organic iodine is then measured by the sum of the apparent renal and thyroidal plasma organic iodine clearances. Two determinations of the $\frac{\text { thyroidal }}{\text { renal }}$ iodide accumulation ratio were employed-the $\frac{\text { thyroidal }}{\text { renal }}$ iodide clearance ratio, and the ratio of thyroidal radioactivity to cumulative urinary radioactivity at the time of peak thyroidal uptake of the administered I ${ }^{131}$ (Table I).

Calculation-In R. D. (Figure 3b) the mean apparent renal plasma organic iodine clearance rate prior to tapazole administration (7th to 10th days inclusive) was 1.0 liters per day. From Table I, the $\frac{\text { thyroidal }}{\text { renal }}$ iodide clearance ratio $=\frac{118}{34}=3.46$ and the $\frac{\text { peak thyroidal uptake }}{\text { renal excretion }}$ ratio $=\frac{80}{26}=3.08$. The mean apparent thyroidal plasma organic iodine clearance is, therefore, 1.0 liters per day $\times 3.46=3.46$ liters per day and 1.0 liters per day $\times 3.08=3.08$ liters per day, respectively, by each of these methods. The sum of thyroidal + renal organic iodine clearances is then 4.46 and 4.08 liters per day. When these figures are multiplied by the plasma $\mathrm{PBI}^{127}$ concentration (154 micrograms per liter), values of 685 and $630 \mathrm{mi}$ crograms per day are obtained for organic iodine degradation.

Degradation rates calculated by these two methods are given under the columns headed Method B and Method C in Table I. Discrepancies between the results of each of these methods are simply a reflection of the experimental errors and biologic factors which make for inequality of the two iodide accumulation ratios. However, comparison of the values obtained by Methods $B$ and $C$ with those calculated by Method A must be viewed with a different significance. In most cases there was substantial agreement, indicating that prior to tapazole administration, urinary $\mathrm{I}^{131}$ was almost entirely in a form which could be accumulated by the thyroid, presumably only iodide. In at least three hyperthyroid subjects (G. J., P. G., and W. R.), however, urinary $\mathrm{I}^{131}$ during tapazole administration (Method A) was much lower than anticipated from the $\frac{\text { thyroidal }}{\text { renal }}$ iodide accumulation ratio (Methods B and C). The discrepancies appear too great to be accounted for on the basis of experimental error or incomplete inhibition by 
tapazole. The implication, therefore, is that in the unblocked state of the gland in these subjects, some fraction of the urinary iodine was organically bound and not subject to thyroidal accumulation. In these cases the calculated plasma iodide levels prior to tapazole administration were the lowest among the patients studied (see Part IV). Thus, a relatively high proportion of organic $\mathrm{I}^{131}$ in the urine may be partly related to a high $\frac{\text { PBI }}{\text { iodide }}$ ratio being presented to the kidneys. Quantitative evaluation of iodide and non-iodide fractions of urinary $\mathrm{I}^{131}$ should permit reliable determinations of the organic iodine degradation rates by this method, in all cases, even in the absence of tapazole inhibition. During tapazole administration, most of the urinary $\mathrm{I}^{131}$ represented iodide previously being accumulated by the thyroid and estimates of the organic iodine degradation rate were then not affected significantly by the presence of small amounts of organic $I^{131}$ in the urine.

In order to minimize errors resulting from changing blood levels and the lag in urinary excretion, the plasma organic iodine clearance measurements were made after the specific activity of the plasma had reached its peak and was changing at a relatively slow rate. ${ }^{5}$ This procedure is also necessary to avoid including in the urinary excretions any iodide ${ }^{131}$ remaining initially from the injected dose which had not been synthesized into an organically bound form by the thyroid; e.g., note the higher excretions over the first few days shown in Figure 3.

B. Estimation of the rate of degradation from the fraction $\Gamma_{\mathrm{ret}}^{131}$ excreted in the urine and the total exchangeable organic iodine pool

The daily organic iodine degradation is also given by the product of the fraction $\mathrm{I}^{131}$ excreted

\footnotetext{
- Since at average normal renal clearance rates, the half time for removal of iodide from the body by the kidneys is about nine hours (2) a brief calculation shows that under these conditions, following thyroid block, the quantity of radioactive iodine excreted in the urine is over 90 per cent on the second day and over 98 per cent thereafter of the amount undergoing degradation. This rapid equilibration between degradation and renal excretion has previously been demonstrated for the metabolism of $I^{131}$ labelled serum albumin (9). In the absence of thyroid inhibition, as is the case prior to tapazole administration, equilibration is even more rapid.
}

in the urine daily during tapazole administration and the total exchangeable organic iodine pool, and may, likewise, be calculated from the urinary excretions prior to tapazole blockage and the $\frac{\text { thyroidal }}{\text { renal }}$ iodide accumulation. Since these determinations can be shown to be mathematically identical to those described in the previous paragraphs, they are not analyzed here in further detail.

\section{Rate of degradation of transfused exogenous biosynthesized organic iodine}

Since distribution of the labeled donor plasma iodine continued for a period of about 48 hours (Figure 6), the rate of degradation could be evaluated only from points taken subsequently. Unfortunately, collections of excreta were incomplete in these cases and so fecal excretion was estimated at $12 \frac{1}{2}$ per cent of degradation (see below). If it is assumed that urinary excretion of undegraded organic iodine was negligible and that in each case the recipient's organic iodine was metabolized at the same rate as the donor's, then the daily degradation rates were 256 micrograms, 68 micrograms, and 13 micrograms in the hyperthyroid, euthyroid and hypothyroid subjects, respectively (Table II).

Hamolsky, Freedberg, Kurland, and Wolsky (10) performed transfusion experiments similar to those presented here. However, these investigators followed the plasma curves for periods of only 23 to 70 hours and assumed that distribution was complete within 4 to 5 hours. In addition, no account was taken of fecal excretion of organic iodine. Their calculated degradation rates, therefore, are probably too high, and their spaces of distribution too low.

\section{The rate of organic iodine degradation as a function of $P B I$ concentration in the plasma}

When the amount of organic iodine degraded daily was plotted against the plasma $\mathrm{PBI}^{127}$ concentrations for all subjects, including the values obtained during periods of declining PBI concentrations under tapazole therapy (Figure 8), it became clear that degradation increases more rapidly than the plasma PBI concentration. The rate of organic iodine degradation was found to be roughly proportional to the square of the 


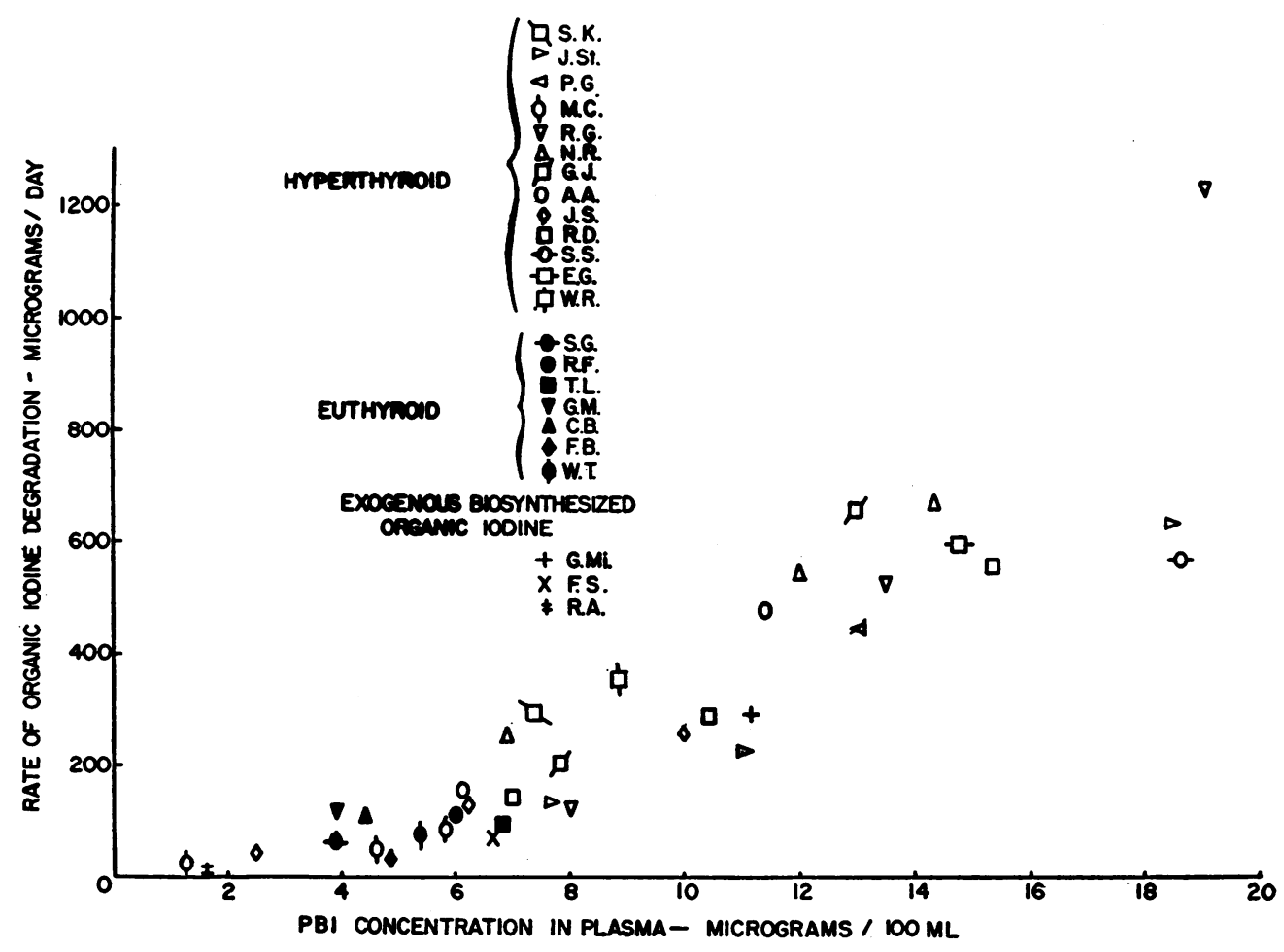

Fig. 8. Rate of Organic Iodine Degradation as a Function of the PBi Concentration in the Plasma

The values for subjects R. D., R. G., N. R., M. C., J. S., A. A., and J. St., which are not included in Table I, were determined from the renal plasma organic iodine clearance rates during the course of tapazole administration as described in the text.

concentration (Figure 9) according to the following formula,

$$
\mathrm{D}=2.94(\mathrm{PBI})^{2} \text {, }
$$

where $\mathrm{D}=$ micrograms organic iodine degraded per day and (PBI) is in micrograms per $100 \mathrm{ml}$. plasma. This relationship is almost in exact agreement with that of Riggs (11) which was derived from data obtained during the administration of exogenous thyroid substance to hypothyroid and euthyroid subjects, and is in line with his suggestion that the metabolism of thyroid hormone is in the nature of a second order reaction.

The biologic life of biosynthesized organic iodine in extrathyroidal tissues is then an inverse function of the plasma concentration, with half times varying from about five days (14 per cent per day) at normal PBI concentrations to less than one and one-half days ( 50 per cent per day) at levels characteristic of marked hyperthyroidism.

\section{E. Fecal excretion of organic iodine}

For the first two or three days following the intravenous administration of $\mathrm{NaI}^{131}$, fecal excretion usually was negligible indicating that iodide is not excreted in the stool to any significant extent. Following the appearance of $\mathrm{PBI}^{131}$ in the plasma, the fecal excretion of organic iodine was calculated from the fecal organic iodine clearance rates.

Calculation-In R. D. (Figure 3b) the fecal organic iodine clearance rate averaged about 0.60 liters per day prior to the administration of tapazole. Since plasma PBI concentration was 154 micrograms per liter, fecal excretion $=.60$ liters per day $\times 154$ micrograms per liter $=93$ micrograms per day. 
Fecal excretion of organic iodine generally amounted to about 10 to 15 per cent of the quantity degraded (Table I). However, there did not appear to be such a striking dependence of the fecal clearance rate on the plasma PBI concentrations as was observed with the degradation process. In hyperthyroid patients with decreasing PBI levels under the influence of tapazole therapy there was an occasional slight decrease in fecal clearance (Figure $3 \mathrm{~b}$ ). Euthyroid subjects appeared to have somewhat lower fecal clearance rates than the hyperthyroid patients but the data do not permit any definite expression of this relationship. In most of the subjects the rate of fecal clearance ranged from about 200 to $450 \mathrm{ml}$. per day. These values may be rederived from Table I by dividing the fecal excretions by the respective plasma PBI concentrations.
PART IV-THE RATE OF REPLACEMENT OF THE ORGANIC IODINE POOL WITH NEWLY INGESTED IODINE; ENDOGENOUS AND EXOGENOUS IODINE BALANCE

\section{A. Organic iodine replacement rate and thyroidal uptake of exogenous iodine}

In subjects who are in the steady state, synthesis of thyroid hormone from newly ingested food iodine (exogenous iodine) must replace that lost by excretion of previously synthesized organic iodine (endogenous iodine). Assuming steady state conditions, the organic iodine replacement rate may then be calculated as the sum of urinary and fecal excretions of endogenous iodine prior to tapazole administration divided by the total exchangeable organic iodine pool.

Calculation-In R. D. (Figure 3b) renal organic iodine clearance prior to tapazole administration was 1.0 liters per day. Since

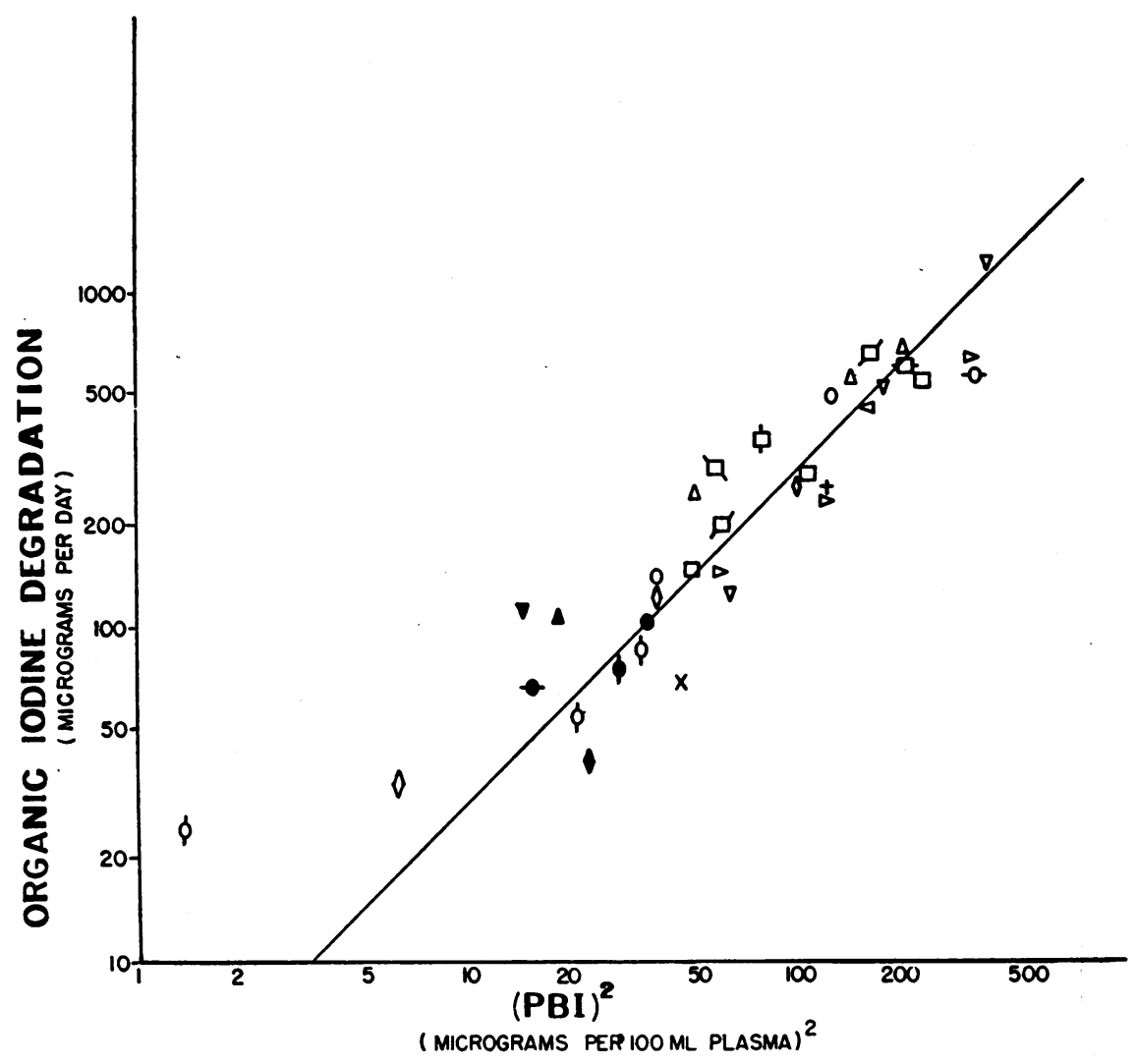

Fig. 9. Log-Log Plot of Organic Iodine Degradation as a Function of the SQuare of the PBI Concentration

The equation fitting the line is $\mathrm{D}=2.94(\mathrm{PBI}) .^{2}$ 
the plasma PBI concentration was $154 \mathrm{mi}-$ crograms per liter, the urinary excretion was 154 micrograms per day. Fecal excretion was 93 micrograms per day and, therefore, thyroidal uptake of exogenous iodine $=154$ $+93=247$ micrograms per day. Then, the fraction of the total pool $(10,300$ micrograms, as calculated above) replaced daily by exogenous iodine $=\frac{247}{10,300}=2.4$ per cent per day.

Values for thyroidal uptake of exogenous iodine and the rate of organic iodine replacement are given in Table III. As expected, the replacement rates were higher in subjects with small pools and lower in those with large pools. Data are not given for subjects recently treated with tapazole since there is evidence to indicate that they may be in periods of positive iodine balance as a result of previous depletion of the thyroid glands.

Theoretically, the organic iodine replacement rate may be derived from the thyroidal and plasma radioactivity curves as follows. If thyroidal and extrathyroidal radioactivities are expressed as fractions of the administered dose of $\mathrm{I}^{181}$, the following equations obtain (Appendix),

$$
\begin{aligned}
& T=\left(T_{p}-c\right) e^{-\lambda_{1} t}+c e^{-\lambda_{2} t} \\
& E=k\left(e^{-\lambda_{1} t}-e^{-\lambda_{2} t}\right)
\end{aligned}
$$

where $T$ and $E$ represent the fractions of the administered dose of $\mathrm{I}^{131}$ in the respective compartments at any time, $t$, following peak uptake, $T_{p}$ is the fraction of the administered dose in the thyroid at peak uptake and $\lambda_{2}$ closely approximates the rate of exchange of newly ingested iodine with the total exchangeable organic iodine pool (organic iodine replacement rate). This is the rate at which the total exchangeable iodine pool would initially decrease, if iodine intake were abruptly discontinued and is clearly distinguished from the total turnover of organic iodine within the body which may be defined as the rate of thyroidal iodide accumulation or organic iodine secretion divided by the total exchangeable organic iodine pool. These equations are not very useful from the practical standpoint since the rate of organic iodine replacement (Table III), is usually too small (1 to 2 per cent per day) to permit accurate evaluation of this rate within the period of time limited by the rate of decay of the isotope. However, the equations do indicate that distribution in the extrathyroidal pool contributes significantly to the early biologic decay curve of thyroidal radioactivity. It is only after distribution equilibrium is attained (5 to 10 days in most of the cases presented here) that the loss from the thyroid parallels loss from the body and can be

TABLE III

\begin{tabular}{|c|c|c|c|c|c|c|c|c|c|}
\hline \multirow[b]{2}{*}{ Subject } & \multirow[b]{2}{*}{$\begin{array}{l}\text { Diag. } \\
\text { No." }\end{array}$} & \multicolumn{3}{|c|}{ Endogenous iodine } & \multicolumn{2}{|c|}{ Exogenous iodine } & \multirow[b]{2}{*}{$\begin{array}{c}\text { Total } \\
\text { iodine } \\
\text { intake } \\
\text { mg./day }\end{array}$} & \multirow{2}{*}{$\begin{array}{l}\text { Organic } \\
\text { iodine } \\
\text { replace- } \\
\text { ment rate } \\
\text { \%/day }\end{array}$} & \multirow{2}{*}{$\begin{array}{c}\text { Calculated } \\
\text { mean plasma } \\
\text { iodide } \\
\text { concentration } \\
\text { Mg./100 ml. }\end{array}$} \\
\hline & & $\begin{array}{c}\text { Renal } \\
\text { excretion }\end{array}$ & $\begin{array}{c}\text { Fecal } \\
\text { excretion } \\
\text { ms./day }\end{array}$ & $\begin{array}{l}\text { Thyroid } \\
\text { uptake }\end{array}$ & 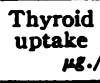 & $\begin{array}{l}\text { Renal } \\
\text { excretion } \\
\text { day }\end{array}$ & & & \\
\hline 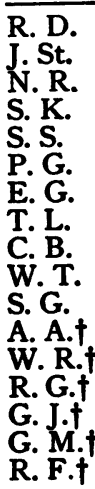 & $\begin{array}{l}\mathbf{H} \\
\mathbf{H} \\
\mathbf{H} \\
\mathbf{H} \\
\mathbf{H} \\
\mathbf{H} \\
\mathbf{H} \\
\mathbf{E} \\
\mathbf{E} \\
\mathbf{E} \\
\mathbf{E} \\
\mathbf{H} \\
\mathbf{H} \\
\mathbf{H} \\
\mathbf{H} \\
\mathbf{E} \\
\mathbf{E}\end{array}$ & $\begin{array}{r}154 \\
88 \\
105 \\
75 \\
43 \\
67 \\
89 \\
81 \\
44 \\
55 \\
47\end{array}$ & $\begin{array}{r}93 \\
81 \\
65 \\
26 \\
62 \\
41 \\
59 \\
13 \\
9 \\
5 \\
20\end{array}$ & $\begin{array}{r}401 \\
556 \\
565 \\
221 \\
-378 \\
501 \\
26 \\
64 \\
21 \\
20\end{array}$ & $\begin{array}{r}247 \\
169 \\
170 \\
101 \\
105 \\
108 \\
148 \\
94 \\
53 \\
60 \\
67\end{array}$ & $\begin{array}{r}76 \\
27 \\
32 \\
40 \\
9 \\
10 \\
17 \\
291 \\
65 \\
180 \\
240\end{array}$ & $\begin{array}{l}323 \\
196 \\
202 \\
141 \\
114 \\
118 \\
165 \\
385 \\
118 \\
240 \\
307\end{array}$ & $\begin{array}{l}2.4 \\
1.9 \\
1.6 \\
.52 \\
2.5 \\
1.2 \\
.84 \\
3.9 \\
.81 \\
5.0 \\
2.4\end{array}$ & $\begin{array}{l}.38 \\
.22 \\
.29 \\
.19 \\
.10 \\
.19 \\
.26 \\
.87 \\
.68 \\
.13 \\
.53 \\
.11 \\
.38 \\
.22\end{array}$ \\
\hline
\end{tabular}

Derived data for iodine balance

* H-Hyperthyroid.

E-Euthyroid.

+ Fecal excretions were not obtained in these subjects. The plasma iodide concentrations were estimated by assuming that fecal excretion of organic iodine was $12 \frac{1}{2}$ per cent of the value obtained for organic iodine degradation. 
taken as reflecting the rate of replacement of body organic iodine (Appendix). At this time the thyroidal and plasma curves should decrease exponentially with essentially the same slope.

\section{B. Estimation of iodine intake}

From the values for thyroidal uptake of exogenous iodine as derived above, the renal excretions of exogenous iodine were calculated, utilizing the $\frac{\text { renal }}{\text { thyroidal }}$ iodide accumulation ratios. When both ratios were available the mean value was utilized for these calculations. Since fecal excretion of iodide is negligible, the iodine intake is then given by the sum of exogenous iodine accumulated by the thyroid and that excreted in the urine. In order to complete the balance sheet, thyroid uptake of endogenous iodine (Table III) is calculated from the increase in renal excretion of radioiodine following tapazole administration or from the renal excretion and the $\frac{\text { thyroidal }}{\text { renal }}$ iodide accumulation ratio in cases where tapazole was not administered.

\section{Estimation of mean plasma iodide concentra- tions}

Since daily thyroidal accumulation (endogenous plus exogenous iodine) is equal to the product of the daily thyroidal clearance of iodide and the mean plasma iodide concentration, the latter could be calculated from the other data available. The calculated plasma iodide concentrations ranged from 0.1 to 0.5 microgram per liter plasma in all but two subjects for whom sufficient data were available (Table III). There appeared to be no consistent differences between euthyroid and hyperthyroid subjects, except that the lowest calculated iodide concentrations were obtained in patients with markedly elevated thyroidal clearance rates.

\section{DISCUSSION}

The studies presented give no insight into the qualitative aspects of iodine metabolism. Future investigations into the relative roles of thyroxine, tri-iodo-thyronine and other possible physiologically important iodine compounds undoubtedly will modify the meaning of any quantitative data regarding total iodine metabolism. However, the parallel relationship between thyroidal activity, tissue metabolism and clinical state, on one hand and total thyroidal iodine accumulation and release and peripheral organic iodine degradation on the other, give significance to such data even in the absence of information regarding the specific hormonally active substances. Results obtained in the cases studied indicate that this parallel relationship obtains in general, regardless of the pathological state of the thyroid gland. There is no evidence to suggest any peripheral abnormality in patients with Graves' disease since so-called "utilization" of "hormonal" iodine appeared to be related primarily to the concentration of circulating organic iodine.

\section{Mixing of the $I^{181}$ tracer in the thyroidal organic iodine pool}

Since there is some histologic evidence for variability of functional activity in different areas of the thyroid, it is perhaps somewhat surprising that the radioiodine tracer appears to $\mathrm{mix}$ so uniformly with the thyroidal pool. However, the maintenance of horizontal plateaus in the plasma concentration curves (fraction $\mathrm{I}_{\text {rot }}^{131}$ ) for two to three weeks prior to tapazole and the constancy of the plasma specific activity even after depletion of 80 to 90 per cent of thyroidal radioactivity under tapazole therapy leave little doubt as to the uniformity of distribution of the $I^{131}$ in a "functional" thyroid pool in these cases. Further confirmation is provided by the general agreement between thyroidal secretion following tapazole block and the sum of organic iodine degradation and excretion. On the other hand, it must be suspected that, not infrequently, labelling of the thyroidal pool with radioactive iodine may be much less uniform, especially in cases of functioning adenomata and in glands of low activity. Such may actually have been the situation in G. M., the only case in which a plateau in the plasma was not reached during the period of observations. If uniform mixing is not obtained, then measurements of the thy roidal pool and the rate of thyroidal secretion after tapazole block may be inaccurate. However, even if so, the lack of reliability of these measurements has no influence whatever on the validity of the calculations for organic iodine degradation, fecal excretion, extrathyroidal space of organic iodine distribution and the size of the 
extrathyroidal pool, all of which are independent of uniformity of mixing of the tracer in the thyroidal pool.

\section{Concentration of $P B I^{131}$ in the plasma as a diag- nostic aid}

Numerous studies have employed the plasma concentration of $\mathrm{PBI}^{131}$ as a measure of thyroidal function. The plasma concentration of $\mathrm{PBI}^{131}$ is influenced by the following factors: The fraction of the administered dose accumulated by the thyroid (which is determined by the ratio of thyroidal to renal iodide clearance), the rate of secretion of organically bound iodine by the thyroid, the size of the thyroidal organic iodine pool, the extrathyroidal space of distribution of organic iodine, the rates of peripheral metabolism and fecal excretion and the time following administration. For any early time the three most important factors are the fraction of the dose accumulated, the size of the thyroidal pool, and the rate of secretion from the thyroid. The first of these is affected by the level of renal clearance and is, therefore, sensitive to an extrathyroidal influence. Moreover, under certain circumstances, changes in the size of the thyroidal pool may so outweigh the effect of the other factors as to result in disparately high or low values for $\mathrm{PBI}^{131}$. Blom and Terpstra (12) and Ingbar, Freinkel, Hoeprich, and Athens (13) have observed cases of post-thyroidectomy myxedema with high $\mathrm{PBI}^{131}$ concentrations in the plasma and have interpreted this as resulting from a small thyroidal pool. In the present study most of the euthyroid subjects previously treated for hyperthyroidism by surgical or radioiodine ablation of the thyroid had small thyroidal pools and high plasma concentrations of $\mathrm{PBI}{ }^{131}$, the latter reaching levels of 0.4 per cent of the administered dose per liter plasma on the third or fourth day. In patients with thyroid toxicity persisting after $I^{131}$ therapy, Chapman, Maloof, Maisterrena, and Martin (14) were puzzled to explain 48-hour thyroidal uptakes of only about 48 per cent. It is reasonable to suggest that the $I^{131}$ therapy had reduced the size of the functional thyroidal pool so that at 48 hours the thyroidal uptakes were significantly below the peak uptake values as a result of secretion into the extrathyroidal pool. Even in untreated cases of hyperthyroidism a fall in thyroidal radioactivity of 10 to 15 per cent from peak uptake to the 48-hour point is not uncommon. An example of the opposite situation is presented by S. K., a hyperthyroid subject with a thyroidal pool of almost 20,000 micrograms iodine who showed a peak concentration in the plasma of only 0.15 per cent of the administered dose per liter and less than 0.1 per cent on the third day. It is clear that the diagnosis of relapse of hyperthyroidism after therapy of Graves' disease should not be influenced by high plasma $\mathrm{PBI}^{131}$ concentrations and also that occasional cases of hyperthyroidism with large thyroidal iodine pools may fail to show high $\mathrm{PBI}^{131}$ concentrations in the plasma.

\section{Effect of tapazole on thyroid secretion}

The nature of the factors controlling iodine release from the thyroid during tapazole administration is not clear. For the first few days, release did not appear to be affected as judged by comparison with the values obtained from the distribution curves prior to tapazole blockage, and those determined for the sum of peripheral degradation and fecal excretion at the same time. In hyperthyroid subjects, thyroidal secretion is definitely retarded after several days of tapazole therapy but this may be related to the decrease in the organic iodine content of the thyroid rather than to a specific effect of tapazole. In view of the falling plasma PBI levels, the decrease in the rate of release of thyroidal iodine is unlikely to be due to diminished pituitary secretion of TSH. Perhaps the thyroid itself is sensitive to changes in its hormonal iodine content and acts to prevent a rapid depletion of iodine stores. An alternative possibility is that an increase in the thyroidal iodide pool, resulting from inhibition of binding, may directly or indirectly effect a decrease in the rate of release of organic iodine by the thyroid. This would be consistent with the effect of iodine administration which also retards release of hormone and yet increases both the organic iodine and iodide contents of the thyroid, at least temporarily. The maintenance of low thyroidal iodide concentrations with thiocyanate or similar agents may aid in the evaluation of the alternative possibilities.

These studies do not confirm Riggs' suggestion (11) that tapazole may increase discharge from the thyroid. For in that event either the plasma PBI ( $I^{127}$ and $\left.I^{131}\right)$ levels should have risen or the 
rate of degradation should have increased over that prior to the administration of tapazole. No significant changes in these directions were ever observed. Furthermore, the values for thyroidal secretion during the first few days of tapazole administration agreed quite reasonably with those obtained independently for the sum of organic iodine degradation and fecal loss. Had tapazole accelerated the rate of thyroidal secretion significant discrepancies should have been observed.

\section{Therapeutic implications}

Since seven to nine per cent of the total iodine pool is degraded daily in some of the hyperthyroid patients, it is evident that complete blockage of iodine accumulation by the thyroid must soon lead either to depletion of available hormone stores or to a significant reduction in the rate of organic iodine degradation and, therefore, to the rapid remission of clinical symptoms. This serves to explain why the most toxic patients often exhibit the most dramatic clinical response to this type of high dosage therapy. The lower dose levels commonly employed in the treatment of hyperthyroidism generally permit thyroidal reaccumulation of 40 per cent or more of iodide released by degradation of organic iodine, as indicated by $I^{131}$ tracer studies (4). Under these conditions the iodine stores are depleted much less rapidly. Since patients treated with the higher doses (25 mg. every six hours) do not exhibit an increased frequency of toxic reactions, it would seem advisable to institute therapy with completely inhibiting doses and to reduce the dosage only after a euthyroid state has been attained.

\section{SUMMARY AND CONCLUSIONS}

1. Methods are presented for the determination of the exchangeable organic iodine pool and the rates of thyroidal secretion, peripheral degradation, and fecal excretion of endogenously synthesized organically bound iodine. These determinations require only assays of radioactivity following the administration of $\mathrm{I}^{181}$ and measurements of the protein bound iodine concentration in the plasma.

The distribution and degradation of exogenously synthesized organically bound iodine were studied in three subjects.

2. The exchangeable thyroidal pool of organic iodine does not differ markedly in untreated hyperthyroidism and euthyroidism but may be strikingly reduced following ablation therapy or treatment with tapazole. The apparent extrathyroidal space of distribution of biosynthesized organic iodine averages about 9 liters or 10 to 20 per cent of body weight.

3. At normal serum PBI levels, approximately 40 to 110 micrograms of iodine are degraded daily in euthyroid subjects and in patients with hyperthyroidism maintained in a euthyroid state clinically by treatment with tapazole. The rate of degradation increases with the square of the PBI concentration over a greater than five-fold range in concentration. There was good agreement between the values obtained for thyroidal secretion and the sum of degradation plus fecal loss.

4. Fecal excretion of organic iodine amounts to approximately 10 to 15 per cent of the quantity degraded in all subjects.

5. Data for exogenous and endogenous iodine balance are derived from the assumption of steady state conditions.

6. The kinetics of distribution and degradation of organic iodine are analyzed and discussed with particular reference to the significance of plasma $\mathrm{PBI}^{131}$ concentrations and the characteristics of the biologic decay curve of thyroidal radioactivity.

7. Certain therapeutic implications of these studies are considered.

\section{APPENDIX}

Let $\mathrm{T}$ and $\mathrm{E}$ represent the fractions of the administered dose of $\mathrm{I}^{121}$ in thyroidal and extrathyroidal compartments at any time, $t$, following peak uptake by the thyroid, $\lambda_{\mathrm{TR}}$ and $\lambda_{\mathrm{Ex}}$ be the rate constants of transfer between the two compartments respectively in the order of the subscript designations and $\lambda_{\mathrm{EV}}$ and $\lambda_{\mathrm{Er}}$ be the rate constants of transfer from the extrathyroidal compartments to urinary and fecal excretions respectively. Let $\lambda_{\mathrm{EO}}=\lambda_{\mathrm{EU}}+\lambda_{\mathrm{EF}}$. Then,

$$
\begin{aligned}
& \frac{d T}{d t}=-\lambda_{T E} T+\lambda_{E T} E \\
& \frac{d E}{d t}=\lambda_{T E} T-\lambda_{E T} E-\lambda_{E O} E
\end{aligned}
$$

Utilizing the conditions, at $\mathrm{t}=0, \mathrm{E}=0$ and $\mathrm{T}=\mathrm{T}_{\mathrm{p}}$ = peak uptake by the thyroid, the equations are solved for $T$ and $E$,

$$
\begin{aligned}
& T=\left(T_{p}-c\right) e^{-\lambda_{1} t}+c e^{-\lambda_{2} t} \\
& E=k\left(e^{-\lambda_{1} t}-e^{-\lambda_{2} t}\right)
\end{aligned}
$$


where

$$
\begin{aligned}
& \lambda_{1}=\frac{1}{2}\left[\left(\lambda_{\mathrm{TE}}+\lambda_{\mathrm{ET}}+\lambda_{\mathrm{EO}}\right)-\left\{\left(\lambda_{\mathrm{TE}}+\lambda_{\mathrm{ET}}+\lambda_{\mathrm{EO}}\right)^{2}\right.\right. \\
& \left.\left.-4 \lambda_{\mathrm{TE}} \lambda_{\mathrm{EO}}\right\}^{\dagger}\right] \\
& \lambda_{z}=\frac{1}{2}\left[\left(\lambda_{\mathrm{TE}}+\lambda_{\mathrm{ET}}+\lambda_{\mathrm{EO}}\right)+\left\{\left(\lambda_{\mathrm{TE}}+\lambda_{\mathrm{ET}}+\lambda_{\mathrm{EO}}\right)^{2}\right.\right. \\
& \left.-4 \lambda_{\mathrm{TE}} \lambda_{\mathrm{EO}}\right\} \\
& c=\frac{T_{p}\left(\lambda_{\mathrm{TE}}-\lambda_{1}\right)}{\lambda_{2}-\lambda_{1}} \\
& \mathrm{k} \stackrel{!}{=} \frac{\lambda_{\mathrm{TE}} \mathrm{T}_{\mathrm{p}}}{\lambda_{2}-\lambda_{1}}
\end{aligned}
$$

$\lambda_{2}$ and $\lambda_{1}$ will differ maximally as the value of the discriminant in (5) and (6) approaches $\lambda_{\mathrm{TE}}+\lambda_{\mathrm{ET}}+\lambda_{\mathrm{EO}}$. This is approximated when

or

$$
\left(\lambda_{\mathrm{TE}}+\lambda_{\mathrm{ET}}+\lambda_{\mathrm{EO}}\right)^{2} \gg 4 \lambda_{\mathrm{TE}} \lambda_{\mathrm{EO}}
$$

$$
\lambda_{\mathrm{TE}}{ }^{2}+\lambda_{\mathrm{ET}^{2}}+\lambda_{\mathrm{EO}}{ }^{2}+2 \lambda_{\mathrm{ET}} \lambda_{\mathrm{EO}}+2 \lambda_{\mathrm{TE}} \lambda_{\mathrm{ET}} \gg 2 \lambda_{\mathrm{TE}} \lambda_{\mathrm{EO}}
$$

In hyperthyroidism $\lambda_{E T}$ is two to three times $\lambda_{E O}$ and $\lambda_{E T}$ is generally five to ten times $\lambda_{\mathrm{TE}}$. The inequality is then seen to be satisfied. In most cases of euthyroidism where the thyroidal pool is much greater than the extrathyroidal pool, then $\lambda_{\mathrm{ET}} \gg \lambda_{\mathrm{TE}}$ and the inequality is also satisfied. However, in certain cases in which the thyroidal pool is small compared to the extrathyroidal pool, due to ablation therapy or other cause, and in which $\lambda_{E O}$ is large compared to $\lambda_{E T}$, the inequality is seen to be less well satisfied. Therefore in all cases except the last, $\lambda_{1}$ is small compared to $\lambda_{2}$.

The organic iodine replacement rate $(R)$ is defined as

$$
\mathrm{R}=\frac{\lambda_{\mathrm{EO}} \times \text { extrathyroidal pool }}{\text { Total exchangeable pool }}=\frac{\lambda_{E O} E_{\text {pool }}}{\mathrm{E}_{\text {pool }}+\mathrm{T}_{\mathrm{pool}}}
$$

where $E_{\text {pool }}$ and $T_{\text {pool }}$ are the quantities of organic iodine ${ }^{127}$ in the respective pools. Since $\lambda_{T E} T_{\text {pool }}=\left(\lambda_{E O}+\lambda_{E T}\right) E_{p o o l}$, then

$$
\mathrm{R}=\frac{\lambda_{\mathrm{EO}} \lambda_{\mathrm{TE}}}{\lambda_{\mathrm{TE}}+\lambda_{\mathrm{ET}}+\lambda_{\mathrm{EO}}}
$$

The purpose of the following section is to demonstrate that when $\lambda_{1}$ is small compared to $\lambda_{2}, \lambda_{1}$ approximates $R$.

Equation (5) can be rewritten in the form

$$
\begin{aligned}
\lambda_{1}=\frac{1}{2}\left[\left(\lambda_{\mathrm{TE}}+\lambda_{\mathrm{ET}}+\right.\right. & \left.\lambda_{\mathrm{EO}}\right)-\left(\lambda_{\mathrm{ET}}+\lambda_{\mathrm{TE}}+\lambda_{\mathrm{EO}}\right) \\
& \left.\times\left(1-\frac{4 \lambda_{\mathrm{TE}} \lambda_{\mathrm{EO}}}{\left.\lambda_{\mathrm{TE}}+\lambda_{\mathrm{ET}}+\lambda_{\mathrm{EO}}\right)^{2}}\right)^{1}\right]
\end{aligned}
$$

As shown above, $\lambda_{1}$ is small compared to $\lambda_{2}$ when

$$
\frac{4 \lambda_{\mathrm{TE}} \lambda_{\mathrm{EO}}}{\left(\lambda_{\mathrm{TE}}+\lambda_{\mathrm{ET}}+\lambda_{\mathrm{EO}}\right)^{2}} \ll 1
$$

Then,

$$
\left[1-\frac{4 \lambda_{\mathrm{TE}} \lambda_{\mathrm{EO}}}{\left(\lambda_{\mathrm{TE}}+\lambda_{\mathrm{ET}}+\lambda_{\mathrm{EO}}\right)^{2}}\right]^{3} \cong 1-\frac{2 \lambda_{\mathrm{TE}} \lambda_{\mathrm{EO}}}{\left(\lambda_{\mathrm{TE}}+\lambda_{\mathrm{ET}}+\lambda_{\mathrm{EO}}\right)^{2}}
$$

Substituting in (10) and (9),

$$
\lambda_{1} \cong \frac{\lambda_{\mathrm{TE}} \lambda_{\mathrm{EO}}}{\lambda_{\mathrm{TE}}+\lambda_{\mathrm{ET}}+\lambda_{\mathrm{EO}}}=\mathrm{R}
$$

- This is easily recognized as the approximation $(1+x)^{t} \cong 1+\frac{x}{2}$ when $x \ll 1$

\section{ACKNOWLEDGMENTS}

We are greatly indebted to Dr. F. R. Keating, Jr. and Dr. N. B. Myant for critically reviewing the manuscript. We also wish to thank Mr. John Hessian and Mr. Paul Newman for the illustrations and Mrs. Frieda Steiner and Miss Eve Spelke for secretarial assistance.

\section{REFERENCES}

1. Stanley, M. M., The direct estimation of the rate of thyroid hormone formation in man. The effect of the iodide ion on thyroid iodine utilization. J. Clin. Endocrinol., 1949, 9, 941.

2. Berson, S. A., Yalow, R. S., Sorrentino, J., and Roswit, B., The determination of thyroidal and renal plasma $I^{181}$ clearance rates as a routine diagnostic test of thyroid dysfunction. J. Clin. Invest., 1952, 31, 141.

3. Barker, S. B., Humphrey, M. J., and Soley, M. H., The clinical determination of protein-bound iodine. J. Clin. Invest., 1951, 30, 55.

4. Berson, S. A., and Yalow, R. S., The iodide trapping and binding functions of the thyroid gland. In preparation.

5. Rall, J. E., Iodine compounds in the blood and urine of man. J. Clin. Endocrinol., 1950, 10, 996.

6. Albert, A., and Keating, F. R., Jr., The role of the gastrointestinal tract, including the liver, in the metabolism of radiothyroxine. Endocrinology, 1952, $51,427$.

7. Zilversmit, D. B., Entenman, C., and Fishler, M. C., On the calculation of "turnover time" and "turnover rate" from experiments involving the use of labeling agents. J. Gen. Physiol., 1943, 26, 325.

8. Berson, S. A., and Yalow, R. S., The distribution of $I^{131}$ labeled human serum albumin introduced into ascitic fluid: Analysis of the kinetics of a three compartment catenary transfer system in man and speculations on possible sites of degradation. J. Clin. Invest., 1954, 33, 377.

9. Berson, S. A., Yalow, R. S., Schreiber, S. S., and Post, J., Tracer experiments with $I^{131}$ labeled human serum albumin : Distribution and degradation studies. J. Clin. Invest., 1953, 32, 746.

10. Hamolsky, M. W., Freedberg, A. S., Kurland, G. S., and Wolsky, L., The exchangeable thyroid hormonal pool. I. Its magnitude and rate of turnover in various thyroid states in man. J. Clin. Invest., $1953,32,453$.

11. Riggs, D. S., Quantitative aspects of iodine metabolism in man. Pharmacol. Rev., 1952, 4, 284.

12. Blom, P. S., and Terpstra, J., High PBI ${ }^{131}$ concentration in blood of patients with myxedema: preliminary report. J. Clin. Endocrinol., 1953, 13, 989.

13. Ingbar, S. H., Freinkel, N., Hoeprich, P. D., and Athens, J. W., The concentration and significance of the butanol-extractable $I^{131}$ of serum in patients with diverse states of thyroidal function. J. Clin. Invest., 1954, 33, 388.

14. Chapman, E. M., Maloof, F., Maisterrena, J., and Martin, J. M., Ten years' experience with radioactive iodide. J. Clin. Endocrinol., 1954, 14, 45. 